NBER WORKING PAPER SERIES

\title{
FINANCIAL CRISES, DOLLARIZATION, AND LENDING OF LAST RESORT IN OPEN ECONOMIES
}

\author{
Luigi Bocola \\ Guido Lorenzoni \\ Working Paper 23984 \\ http://www.nber.org/papers/w23984 \\ NATIONAL BUREAU OF ECONOMIC RESEARCH \\ 1050 Massachusetts Avenue \\ Cambridge, MA 02138 \\ November 2017, Revised June 2018
}

Previously circulated as "Financial Crises and Lending of Last Resort in Open Economies." First draft: August 29, 2016. We thank Mark Aguiar, Fernando Alvarez, Javier Bianchi, Charles Brendon, Fernando Broner, Alessandro Dovis, Pierre-Olivier Gourinchas, Anton Korinek, Matteo Maggiori, Fabrizio Perri, and participants at EIEF, CSEF-IGIER 2016, EEA-ESEM 2016, Cambridge-INET 2016, ASSA 2017, CREI, PSE, Boston College, Cornell, Carnegie Mellon, Wharton, University of Chicago, MFS 2017 spring meeting, IMF, Federal Reserve Bank of Richmond, SED 2017, NBER SI 2017, ITAM-PIER 2017, Stanford SITE 2017, Federal Reserve Board, Columbia, NYU, Duke, UNC, MIT, Harvard, the BIS, Notre Dame, UCLA, and UBC. Jane Olmstead-Rumsey provided excellent research assistance. The views expressed herein are those of the authors and not necessarily those of the Federal Reserve Bank of Minneapolis, the Federal Reserve System, or the National Bureau of Economic Research.

NBER working papers are circulated for discussion and comment purposes. They have not been peerreviewed or been subject to the review by the NBER Board of Directors that accompanies official NBER publications.

(C) 2017 by Luigi Bocola and Guido Lorenzoni. All rights reserved. Short sections of text, not to exceed two paragraphs, may be quoted without explicit permission provided that full credit, including () notice, is given to the source. 
Financial Crises, Dollarization, and Lending of Last Resort in Open Economies

Luigi Bocola and Guido Lorenzoni

NBER Working Paper No. 23984

November 2017

JEL No. E44,F34,F41,G11,G15

\begin{abstract}
$\underline{\text { ABSTRACT }}$
Foreign currency borrowing is perceived as a source of financial instability in emerging markets. We propose a theory where liability dollarization arises from an insurance motive of domestic savers. Because financial crises are associated with currency depreciations, savers are reluctant to hold assets denominated in local currency. This behavior makes local currency debt expensive, incentivizing borrowers to issue foreign currency debt. We show that this mechanism can generate multiple equilibria, with the bad equilibrium characterized by dollarization and financial instability. A domestic lender of last resort can eliminate the bad equilibrium, but interventions need to be fiscally credible. Holdings of foreign currency reserves hedge the fiscal position of the government and enhance its credibility, thus improving financial stability.
\end{abstract}

\author{
Luigi Bocola \\ Department of Economics \\ Northwestern University \\ 2001 Sheridan Road \\ Evanston, IL 60208 \\ and NBER \\ luigi.bocola@northwestern.edu \\ Guido Lorenzoni \\ Department of Economics \\ Northwestern University \\ 2211 Campus Dr \\ Evanston, IL 60208 \\ and NBER \\ guido.lorenzoni@northwestern.edu
}




\section{Introduction}

Emerging economies are exposed to recurrent episodes of financial instability. At least since the East Asian crisis of 1997, this instability has been linked to the presence of debt denominated in foreign currency issued by banks, firms, or households. These various forms of liability dollarization can amplify the effects of financial crises, as crises are typically associated with currency depreciations, and depreciations increase the real burden of foreign currency debt. Liability dollarization also makes it challenging for domestic authorities to intervene in financial markets when a crisis takes place: covering the losses of local borrowers by expanding domestic money supply can lead to inflationary concerns and exacerbate the currency depreciation, while using government borrowing may lead to concerns about public debt sustainability.

While we have a good understanding of the mechanisms by which foreign currency debt makes emerging economies more fragile, we still have a relatively limited understanding of the incentives that drive the accumulation of foreign currency debt in the first place. In this paper we build a theory of liability dollarization and study how it interacts with policy interventions, focusing in particular on operations of lending of last resort.

Our theory builds on two observations emphasized in recent empirical work. First, countries characterized by high levels of liability dollarization are also countries where domestic agents tend to save in foreign currency. ${ }^{1}$ Second, local currency bonds in these economies are characterized by positive excess returns over comparable dollar bonds, which effectively means that borrowing in dollars is cheaper than borrowing in local currency. ${ }^{2}$ In our theory, both facts are driven by the incentives of domestic savers to insure against a crisis. Because crises are associated with a depreciation of the local currency, domestic savers are reluctant to hold local currency assets. This behavior puts upward pressure on local currency interest rates, incentivizing domestic borrowers to issue debt in foreign currency. We show that this mechanism can lead to multiple equilibria, with a bad equilibrium characterized by higher excess returns on domestic currency bonds, more financial dollarization, and a higher probability of crises. In line with this logic, and in contrast with the conventional view, we also show that ex-post government interventions that reduce financial instability can induce the private sector to take safer choices ex ante: by reducing savers' demand for insurance, they can lead in equilibrium to lower levels of liability dollarization.

\footnotetext{
${ }^{1}$ This correlation is documented in De Nicoló, Honohan, and Ize (2003) and Levy-Yeyati (2006). Arteta (2005) shows that this relation is stronger for countries with more volatile exchange rates.

${ }^{2}$ Burnside, Eichenbaum, and Rebelo (2007) first documented large deviations from uncovered interest rate parity (UIP) for emerging market bonds. Recent work by Dalgic (2017) and Wiriadinata (2017) finds a positive correlation across countries between these UIP deviations and the degree of liability dollarization.
} 
We develop these arguments in a framework that extends a "third-generation" currency crisis model (Krugman, 1999) by adding an explicit treatment of ex ante portfolio decisions of borrowers and savers, in line with recent developments in the macro-financial literature (Gertler and Kiyotaki, 2010; Brunnermeier and Sannikov, 2014; He and Krishnamurthy, 2015). We consider a small open economy populated by two types of domestic agents, consumers and bankers, and by risk-neutral foreign investors. Consumers work for domestic firms and save in bonds denominated in domestic and foreign currency. Bankers borrow in domestic and foreign currency and use these resources along with their accumulated net worth to purchase domestic capital, which is used as input in production. The model features two sources of financial frictions: banks face a potentially binding financial constraint, and foreign investors only borrow and lend in foreign currency.

Our economy is exposed to self-fulfilling crises because of a feedback loop between the exchange rate and banks' net worth. A decline in banks' net worth depresses investment, which reduces expected future wages and consumers' demand for non-tradable goods, causing a real exchange rate depreciation. An exchange rate depreciation, then, reduces banks' net worth if they have foreign currency liabilities and domestic currency assets. Thus, an economy with enough foreign currency debt is exposed to a crisis in which banks' net worth, the real exchange rate, and consumers' income all fall at the same time.

The key aspect of our paper is to study how the comovement caused by financial crises influences the ex ante portfolio decisions of consumers and bankers regarding the currency denomination of their financial positions. When crises are possible in the future, consumers have an incentive to insure by saving in foreign currency because of the hedging properties highlighted above: in a crisis, consumers' income goes down while the foreign currency appreciates. In general equilibrium, this means that the interest rate in domestic currency will be high relative to the interest rate in foreign currency, making foreign currency borrowing relatively cheaper for banks. This mechanism can dominate the banks' own motives to insure against a crisis, leading them to issue more dollar debt.

This feedback between the insurance motives of consumers and the risk of future crises can be so strong as to produce multiple equilibria. In a safe equilibrium, consumers are not worried about future crises and are happy to save in domestic currency, banks borrow mostly in domestic currency, the balance sheet effects of currency depreciation are weak, and crises cannot occur. This confirms consumers' expectations. In a fragile equilibrium, consumers are worried about future crises and save in foreign currency. Domestic currency funding is more expensive, so banks borrow in dollars, making the financial sector more fragile and opening the door to the possibility of a crisis. Again, consumers' expectations are confirmed. This novel form of multiplicity emphasizes the importance of allowing for 
endogenous risk premia as determinants of the currency denomination of debt.

The presence of these fragile equilibria motivates our analysis of lending of last resort. We consider the problem of a benevolent government that can extend a liquidity facility to the banks when a crisis takes place. Although these interventions can break the feedback loop between exchange rates and banks' net worth, we show that a government with limited fiscal resources might be unable to credibly eliminate the crisis equilibrium. The reason is that when private investors hold pessimistic expectations, they also forecast low future tax revenues, and they are reluctant to purchase government debt. This constrains the government's ability to finance the liquidity facilities and to lead the economy out of the crisis. In this context, we show that foreign currency reserves hedge the fiscal position of the government because they appreciate precisely when the private investors hold pessimistic expectations. When sufficiently large, the ex ante accumulation of foreign currency reserves allows the government to credibly operate as a lender of last resort and eliminates the crisis equilibrium.

This last set of results provides a rationale to the view, articulated by several economists and policymakers, that emerging market authorities recently accumulated large quantities of foreign currency reserves in order to improve financial stability. ${ }^{3}$ In our framework, foreign currency reserves help financial stability because they have good hedging properties against bad equilibria. In other words, a desirable feature of foreign currency reserves is that if private sector beliefs deteriorate, pushing the economy toward a crisis, the value of reserves increases, giving the government more resources to intervene.

Importantly, the accumulation of official foreign currency reserves does not induce the banking sector to increase risk taking ex ante, as the standard moral hazard logic would suggest. When the government can credibly rule out financial panics, it also reduces the incentives of domestic savers to hold foreign currency assets for precautionary reasons. Through this mechanism, ex post interventions reduce the costs of borrowing in domestic currency, deterring banks from borrowing in foreign currency. In this sense, official holdings of foreign currency reserves can play a catalytic role by encouraging virtuous behavior of local borrowers and by promoting financial stability also from an ex ante perspective.

Literature. Our research is related to several strands of literature. Following the crises of the late 1990s, several authors have developed equilibrium models to explain the joint occurrence of financial and currency crises. The seminal work of Krugman (1999) empha-

\footnotetext{
${ }^{3}$ For example, in a speech as governor of the Bank of England, Mervyn King argues that the buildup of foreign currency reserves allows emerging market authorities to act as "do-it-yourself lenders of last resort in US dollars to their own financial system" (King, 2006).
} 
sizes how the feedback between investment demand and the real exchange rate can lead to multiple equilibria when firms/financial institutions have dollar debt. Other seminal contributions in this literature include Aghion, Bacchetta, and Banerjee $(2001,2004)$, Burnside, Eichenbaum, and Rebelo (2001b), Corsetti, Pesenti, and Roubini (1999), Chang and Velasco $(2000,2001)$. An important innovation relative to this literature is that we endogenize debt denomination and show how risk premia can lead banks to endogenously choose currency positions that expose an economy to a crisis.

The economic mechanism that produces foreign currency debt in our setting are distinct from other explanations offered in the literature and, in particular, from Schneider and Tornell (2004), Burnside, Eichenbaum, and Rebelo (2001a) and Farhi and Tirole (2012). These papers emphasize the role of bailout guarantees that, coupled with the financial instability typical of emerging markets, can induce the private sector to take excessive risk and borrow in foreign currency. ${ }^{4}$ In contrast, we emphasize the portfolio choices of domestic savers and how their demand for safety can, through a general equilibrium mechanism, incentivize local borrowers to issue dollar debt. As explained earlier, our theory has distinctive predictions for the coexistence of asset and liability dollarization and for deviations from uncovered interest parity that finds support in the data. Another key difference lies in the effects of policy: in the moral hazard view, ex post government interventions generate risk shifting and lead to more dollar debt; in our theory, these interventions can reduce the degree of financial dollarization in the economy.

Our approach to lending of last resort is close to Gertler and Kiyotaki (2015). In their environment, providing liquidity to the financial sector during a panic has ex ante benefits, and it is always optimal ex post because the government does not face borrowing constraints. The main innovation in our paper relative to their approach is that we explicitly formulate a game between the government and private investors, which embeds equilibrium in goods and asset markets. This allows us to analyze whether off-the-equilibriumpath promises to intervene in a "bad" equilibrium are credible and to discuss how limited fiscal capacity can interfere with lending of last resort policies. The only previous work we know of that discusses credibility issues in lending of last resort policies is Ennis and Keister (2009), who analyze deposit freezes in the Diamond and Dybvig (1983) model. ${ }^{5}$

A few papers address financial dollarization from a portfolio perspective. In particular, Ize and Levy-Yeyati (2003) present a model that focuses on the effects of the monetary

\footnotetext{
${ }^{4}$ On the normative side, Caballero and Krishnamurthy (2003) suggest that dollar debt might be excessive relative to the social optimum because of pecuniary externalities.

${ }^{5} \mathrm{~A}$ different approach to think about the fiscal costs of intervention is to consider the policy maker's uncertainty on whether a crisis is due to illiquidity or insolvency, an approach pursued in Robatto (2017).
} 
regime, which determines the volatility of inflation and of the nominal exchange rate. ${ }^{6}$ Salomao and Varela (2017) build a partial equilibrium model of the response of domestic borrowers to UIP violations and use it to generate cross-sectional predictions on the currency composition of debt. Gopinath and Stein (2018) present a model where the choice of debt denomination comes from a stylized portfolio problem and use it to study the complementarity between dollar invoicing and financial dollarization in the international monetary system. A distinctive feature of our paper relative to this literature is the focus on the hedging benefits of dollar assets against financial instability.

An important literature studies the role of foreign currency reserves as insurance against various types of shocks (Caballero and Panageas, 2008; Durdu, Mendoza, and Terrones, 2009; Jeanne and Rancière, 2011; Bianchi, Hatchondo, and Martinez, 2012). Relative to this literature, our focus on reserves' role to fight financial panics leads to a distinct set of predictions. ${ }^{7}$ In particular, our model can rationalize why reserves across countries are well explained by the size of the financial sector's total liabilities, as shown by Obstfeld, Shambaugh, and Taylor (2010). Moreover, our framework can explain why reserves seem to be underutilized by domestic authorities, as documented by Aizenman and Sun (2012). In our framework, a government that accumulates enough reserves can rule out financial panics, so reserves are never used in equilibrium.

Finally, our paper relates to recent research aimed at understanding the patterns of global capital flows and low interest rates in the world economy (Caballero, Farhi, and Gourinchas, 2008; Gourinchas and Jeanne, 2013; Mendoza, Quadrini, and Rios-Rull, 2009; Maggiori, 2017; Fahri and Maggiori, 2017). Our paper offers a fully fledged model of financial instability as a cause for increased accumulation of reserves by emerging economies, and it identifies important differences between the private and the official sector demand for dollars.

Layout. Section 2 presents the model. We then move on to characterize the equilibria of the model, proceeding backward in time. Section 3 describes the continuation equilibria of the model from period 1 onward, taking the currency denomination of assets and liabilities as given. Section 4 studies the optimal portfolio choices of households and banks in the initial period. In Section 5 we introduce a government and study lending of last resort, while Section 6 discusses the role of foreign currency reserves. Section 7 concludes.

\footnotetext{
${ }^{6}$ Rappoport (2009) adds defaultable debt and optimal monetary policy to the setup of Ize and Levy-Yeyati (2003) and obtains the possibility of multiple equilibria due to the endogenous response of monetary policy.

${ }^{7}$ Models that focus on other sources of equilibrium multiplicity are Hur and Kondo (2016) and Hernandez (2017).
} 


\section{Model}

We consider a small open economy that lasts three periods, $t=0,1,2$, populated by two groups of domestic agents, consumers and bankers, who trade with a large number of foreign investors. There are two goods in the economy, a tradable good and a non-tradable good.

The model is built around three ingredients. First, in line with standard financial accelerator models, bankers have unique access to a superior technology to accumulate capital, and they finance capital accumulation with debt. Second, debt can be denominated in nontradable or tradable goods, which is meant to capture debt denominated in domestic and foreign currency. This creates the possibility of currency mismatch. Third, consumers supply labor that is combined with capital to produce tradable output. This last assumption introduces a simple macro spillover by which consumers' incomes go down when bankers' capacity to accumulate capital contracts.

We now turn to a detailed description of the environment. The model includes a number of simplifying assumptions. Their role is discussed in detail at the end of the section.

\subsection{Agents and their decision problems}

Consumers. Consumers have preferences represented by the utility function

$$
\mathbb{E} \sum_{t} \beta^{t} U\left(c_{t}\right)
$$

where $U\left(c_{t}\right)=c_{t}^{1-\gamma} /(1-\gamma)$ and $c_{t}$ is the Cobb-Douglas consumption aggregator

$$
c_{t}=\left(c_{t}^{T}\right)^{\omega}\left(c_{t}^{N}\right)^{1-\omega}
$$

$c_{t}^{T}$ is consumption of the tradable good, and $c_{t}^{N}$ is consumption of the non-tradable good.

The tradable good is the numeraire, and $p_{t}$ denotes the price of the non-tradable good. Each period $t$, consumers supply a unit of labor inelastically at the wage $w_{t}$ and receive an endowment of non-tradable goods $e_{c, t}^{N}$.

Consumers trade one-period bonds denominated in tradable and non-tradable goods, denoted by $a_{t}^{T}$ and $a_{t}^{N}$, at the prices $q_{t}^{T}$ and $q_{t}^{N}$. As just mentioned, these two bonds represent foreign and domestic currency denominated bonds. Currency denomination can be modeled in other ways-for example, by denominating domestic bonds in terms of the domestic consumption basket, or by introducing explicitly nominal variables and making 
assumptions about monetary policy. For our purposes here, simply denominating bonds in tradables and non-tradables makes the analysis more transparent.

The consumers' budget constraint is

$$
c_{t}^{T}+p_{t} c_{t}^{N}+q_{t}^{T} a_{t+1}^{T}+q_{t}^{N} p_{t} a_{t+1}^{N} \leq w_{t}+p_{t} e_{c, t}^{N}+a_{t}^{T}+p_{t} a_{t}^{N}
$$

Consumers choose consumption levels and asset positions in order to maximize their utility subject to the budget constraint (1) and the terminal condition $a_{3}^{N}=a_{3}^{T}=0$.

Bankers. Bankers are risk-neutral agents and consume only tradable goods at date 2 . Bankers own banks. Banks hold physical capital $k_{t}$, which is used as input in the production of tradable goods and yields the rental rate $r_{t}$. Banks have access to a linear technology to convert one unit of tradable goods into one unit of capital and vice versa. Capital fully depreciates at the end of each period. Banks also receive a non-tradable endowment each period $e_{b, t}^{N}$. On the liability side, banks issue tradable and non-tradable denominated bonds, denoted, respectively, by $b_{t}^{T}$ and $b_{t}^{N}$. The banks' net worth at the beginning of each period is

$$
n_{t}=r_{t} k_{t}+p_{t} e_{b, t}^{N}-b_{t}^{T}-p_{t} b_{t}^{N}
$$

The banks' budget constraint at $t=0,1$ is

$$
k_{t+1}=n_{t}+q_{t}^{T} b_{t+1}^{T}+q_{t}^{N} p_{t} b_{t+1}^{N} .
$$

At $t=2$ the bankers consume $n_{2}$.

We assume that banks face limits in their ability to raise external finance. Namely, they have to satisfy the following collateral constraint, which requires total end-of-period liabilities to be bounded, in each state of the world, by a fraction of the capital held by the bank:

$$
b_{t+1}^{T}+p_{t+1} b_{t+1}^{N} \leq \theta k_{t+1},
$$

where $\theta$ is a parameter in $[0,1]$. The underlying assumption is that at the beginning of each period the banker can allow the bank to default on its debt and divert the bank's resources to consume or to start a new bank. Diversion entails a real cost $\theta k_{t}{ }^{8}$

Bankers choose $\left\{k_{t+1}, b_{t+1}^{T}, b_{t+1}^{N}\right\}$ to maximize the expected value of $n_{2}$, subject to the law of motion for net worth (2), the budget constraint (3), the collateral constraint (4), and the terminal condition $b_{3}^{T}=b_{3}^{N}=0$.

\footnotetext{
${ }^{8}$ The banker's participation constraint is then $r_{t} k_{t}+p_{t} e_{b}^{N}-\theta k_{t} \geq r_{t} k_{t}+p_{t} e_{b}^{N}-b_{t}^{T}-p_{t} b_{t}^{N}$, which gives (4).
} 
Production. Consumers own two types of firms. Tradable goods firms produce tradable goods using capital and labor according to the production function

$$
y_{t}^{T}=K_{t}^{\alpha} L_{t}^{1-\alpha}
$$

where $K_{t}$ and $L_{t}$ are capital and labor inputs.

Next, there are firms that produce capital $\tilde{k}_{t}$ using a linear technology that requires $\phi>1$ units of tradable goods per unit of capital. Since the latter technology is inferior to the banks' technology, these firms will only be active when banks' capital is low enough, as we will see shortly.

Both types of firms owned by consumers run constant returns to scale technologies, so their profits will be zero in equilibrium and can be omitted from the consumers' budget constraints.

We assume that the total endowment of non-tradable goods is constant over time:

$$
e_{c, t}^{N}+e_{b, t}^{N}=e^{N}
$$

Foreign investors. Foreign investors are risk neutral and consume only tradable goods. Their discount factor is $\beta$. An important restriction in our model is that foreign investors can only purchase tradable denominated bonds, denoted by $\left\{a_{t}^{T *}\right\}$.

\subsection{Equilibrium}

There are no fundamental shocks in the economy, but given the possibility of multiple equilibria, we introduce a sunspot variable $\zeta$ realized at $t=1$, with a uniform distribution on $[0,1]$, and use this sunspot as a selection device when multiple equilibria are possible at $t=1$. For ease of notation, we will mostly leave implicit the dependence of variables dated $t=1,2$ on the sunspot realization. ${ }^{9}$

Definition 1. A competitive equilibrium is a vector of prices $\left\{p_{t}, r_{t}, w_{t}, q_{t}^{T}, q_{t}^{N}\right\}$, households' choices $\left\{c_{t}^{T}, c_{t}^{N}, a_{t+1}^{T}, a_{t+1}^{N}\right\}$, bankers' choices $\left\{k_{t+1}, b_{t+1}^{T}, b_{t+1}^{N}\right\}$, firms' choices $\left\{K_{t}, L_{t}, \tilde{k}_{t}\right\}$, and foreign investors' choices $\left\{a_{t}^{T *}\right\}$ such that all choices are individually optimal and all markets clear,

$$
c_{t}^{N}=e^{N}, \quad a_{t}^{T}+a_{t}^{T *}=b_{t}^{T}, \quad a_{t}^{N}=b_{t}^{N}, \quad K_{t}=k_{t}+\tilde{k}_{t} .
$$

\footnotetext{
${ }^{9}$ We only introduce a sunspot at $t=1$ because, conditional on past state variables, no multiplicity can arise at $t=2$, and we do not need to specify how multiplicity is resolved at $t=0$, given that no previous decision relies on that equilibrium selection.
} 
For simplicity, throughout the paper we focus on economies in which at date $t=0$, in equilibrium, there is no investment in the inferior technology, that is, $K_{1}=k_{1}$ and $\tilde{k}_{1}=0$.

\subsection{Discussion of assumptions}

Let us briefly discuss some simplifying assumptions made in the model.

First, banks invest directly in physical capital, rather than making loans. This is a fairly common assumption in the financial accelerator literature, and it essentially consolidates into a unique entity the banks and the firms they lend to. In terms of capturing the problem of liability dollarization, this assumption treats in the same way situations in which banks' balance sheets are explicitly mismatched and situations in which they are only implicitly mismatched-as happens, for example, when banks borrow in dollars and lend in dollars to domestic firms, who are then more likely to default in the event of a depreciation.

Second, foreign investors in the model can only hold tradable bonds, an assumption that plays an important role in our analysis, as we will discuss in Section 4.4. Our results, however, do not require this stark form of segmentation, and they would go through as long as the demand for domestic currency (non-tradable) claims by foreigners is not infinitely elastic. Ruling out foreign investors' participation in the domestic currency debt market is just a useful simplification.

Third, we are assuming that non-tradables are in fixed endowment. This simplifies the analysis because we do not have to determine how labor is allocated among the two sectors and only need to keep track of capital accumulation in one sector. Our main results can also be derived in a more symmetric version of the model with production in both sectors, but the analysis is less transparent.

\subsection{Road map}

In the next two sections, we analyze the model in two steps, moving backward in time. First, we analyze the equilibrium in the last two periods, taking as given assets and liabilities from the previous period. We call this a continuation equilibrium and show that, for some initial conditions, multiple continuation equilibria are possible. In our second step, we go back to date 0 and complete our equilibrium characterization, focusing, in particular, on the endogenous denomination of assets and liabilities and on whether the economy can endogenously settle on portfolios that produce multiple continuation equilibria. 


\section{Financial crises}

In this section, we look at continuation equilibria, that is, equilibria that arise at dates $t=1,2$, for given initial asset positions $\left\{a_{1}^{T}, a_{1}^{N}, b_{1}^{T}, b_{1}^{N}, K_{1}\right\}$. We characterize continuation equilibria using two relations. The first is an equilibrium condition in the non-tradable goods market. The second is an equilibrium condition in the capital market.

\subsection{Non-tradable goods market}

Simple derivations in the appendix show that the price of non-tradable goods is constant in periods $t=1,2$ and is determined by the market clearing condition

$$
\frac{1}{p} \frac{1-\omega}{1+\beta}\left(a_{1}^{T}+p a_{1}^{N}+w_{1}+\beta w_{2}+p\left(e_{c, 1}^{N}+\beta e_{c, 2}^{N}\right)\right)=e^{N},
$$

where $p$ denotes the constant price of non-tradables in $t=1,2$. The left-hand side of this equation is the demand for non-tradables: consumers spend a fraction $(1-\omega) /(1+\beta)$ of their lifetime wealth on non-tradable goods, and their wealth is equal to their financial wealth plus the present value of their labor income and non-tradable endowments. ${ }^{10}$ The right-hand side of the equation is just the total supply of non-tradables. Profit maximization and labor market clearing imply that wages are $w_{t}=(1-\alpha) K_{t}^{\alpha}$. So we can rearrange the equation above to express $p$ as a function of $K_{2}$ :

$$
p=\mathcal{P}\left(K_{2}\right) \equiv(1-\omega) \frac{(1-\alpha)\left(K_{1}^{\alpha}+\beta K_{2}^{\alpha}\right)+a_{1}^{T}}{(1+\beta) e^{N}-(1-\omega)\left(e_{c, 1}^{N}+\beta e_{c, 2}^{N}\right)-(1-\omega) a_{1}^{N}}
$$

To ensure that the non-tradable goods market clears at a finite price $p$, claims $a_{1}^{N}$ denominated in non-tradable goods must satisfy

$$
(1-\omega) a_{1}^{N}+(1-\omega)\left(e_{c, 1}^{N}+\beta e_{c, 2}^{N}\right)<(1+\beta) e^{N}
$$

which implies that the denominator in (7) is positive.

Equation (7) defines an increasing relation between $p$ and $K_{2}$. More capital invested in the tradable sector leads to higher wages in period 2, higher consumers' wealth, and higher demand for non-tradables. This leads to a real appreciation (higher $p$ ). This mechanism is a version of the Balassa-Samuelson effect.

\footnotetext{
${ }^{10}$ The real interest rate is $1 / \beta$ due to the presence of international investors with linear preferences.
} 


\subsection{Capital market}

In the capital market, three configurations are possible.

First, banks' net worth may be large enough that the collateral constraint is slack. In this case, banks' optimality requires $\beta r_{2}=1$. Substituting the rental rate $r_{2}=\alpha K_{2}^{\alpha-1}$ and solving, we get the first-best level of capital

$$
K_{2}=K^{*}=(\alpha \beta)^{\frac{1}{1-\alpha}} \text {. }
$$

Given that banks can borrow at most $\beta \theta k_{2}$, this case arises if banks' net worth satisfies $n_{1} \geq(1-\beta \theta) K^{*}$.

A second scenario arises if the banks' collateral constraint is binding, but there is no investment in the inferior capital accumulation technology controlled by the consumers. In this case, the level of $K_{2}$ can be derived from the bankers' budget constraint:

$$
K_{2}=\frac{1}{1-\beta \theta} n_{1}
$$

To ensure that banks find it optimal to invest in capital and that the inferior technology is not in use, $K_{2}$ must satisfy the inequalities

$$
1 \leq \beta r_{2}=\beta \alpha K_{2}^{\alpha-1} \leq \phi
$$

In the third scenario, the bankers' net worth is so low that there is positive investment in the inferior technology. Optimality for the firms running this technology requires $\beta r_{2}=\phi$, which yields the aggregate capital stock

$$
K_{2}=\underline{K} \equiv(\alpha \beta / \phi)^{\frac{1}{1-\alpha}}
$$

This case arises if bank's net worth satisfies $n_{1} \leq(1-\beta \theta) \underline{K}$. In this case, banks' investment is $k_{2}=n_{1} /(1-\beta \theta)$, and investment in the inferior technology is $\tilde{k}_{2}=\underline{K}-k_{2}>0 .{ }^{11}$

To complete the analysis of the capital market, notice that the banks' net worth from equation (2) is a linear function of the non-tradable price:

$$
n_{1}=N(p) \equiv \alpha K_{1}^{\alpha}-b_{1}^{T}+p\left(e_{b, 1}^{N}-b_{1}^{N}\right)
$$

\footnotetext{
${ }^{11}$ An additional case arises if the net worth $n_{1}$ is negative. Dealing with this case would require specifying how banks' bankruptcy is resolved for bondholders. In what follows, we will provide conditions that rule out this case.
} 
Combining this relation with the analysis of the three cases discussed above, we obtain the following schedule:

$$
K_{2}=\mathcal{K}(p) \equiv\left\{\begin{array}{lll}
K^{\star} & \text { if } \quad N(p) \geq(1-\beta \theta) K^{*} \\
\underline{K} & \text { if } \quad N(p)<(1-\beta \theta) \underline{K} \\
\frac{1}{1-\beta \theta} N(p) & \text { otherwise. }
\end{array}\right.
$$

From now on, we restrict attention to date 1 positions that satisfy three inequalities:

$$
b_{1}^{N} \leq e_{b, 1}^{N}, \quad b_{1}^{T} \leq \theta K_{1}, \quad \alpha K_{1}^{\alpha-1} \geq 1 / \beta
$$

The first inequality means that banks have a non-negative net position in non-tradables, so a real exchange rate appreciation (higher $p$ ) increases banks' net worth and leads to (weakly) higher investment. We focus on initial asset positions that satisfy this inequality because this is the interesting case that can potentially produce multiple equilibria.

The other two inequalities are just necessary conditions for the optimality of the bankers at date 0 and must be satisfied in any competitive equilibrium. The second inequality is a necessary condition for the collateral constraint (4) at $t=0$, while the third inequality is a necessary condition for banks' optimal choice of $K_{1}$ at date 0 .

Combining the three inequalities above implies that the banks' net worth is always positive, since

$$
n_{1}=\alpha K_{1}^{\alpha}-b_{1}^{T}+p_{1}\left(e_{b, 1}^{N}-b_{1}^{N}\right)>\theta K_{1}-b_{1}^{T} \geq 0 .
$$

\subsection{Multiple equilibria}

Continuation equilibria can be found looking for pairs $\left(K_{2}, p\right)$ that satisfy $p=\mathcal{P}\left(K_{2}\right)$ and $K_{2}=\mathcal{K}(p)$. Using the concavity of the function $\mathcal{P}$ and the properties of the capital demand $\mathcal{K}$, we can then prove the following.

Proposition 1. Suppose initial asset positions $\left\{a_{1}^{T}, a_{1}^{N}, b_{1}^{T}, b_{1}^{N}, K_{1}\right\}$ satisfy (8) and (10). Then a continuation equilibrium exists and there are at most three continuation equilibria. If there are multiple equilibria, the equilibrium with the lowest price always has $K_{2}=\underline{K}$.

Figure 1 plots two examples of the schedules $\mathcal{P}$ and $\mathcal{K}$ in the $\left(K_{2}, p\right)$ space. An equilibrium corresponds to a point where the two schedules intersect. In panel (a) there is a unique equilibrium. In panel (b) there are three equilibria, at points $A, B$, and $C$. In equilibrium $A$, banks are unconstrained. In equilibria $B$ and $C$, however, the collateral constraint 


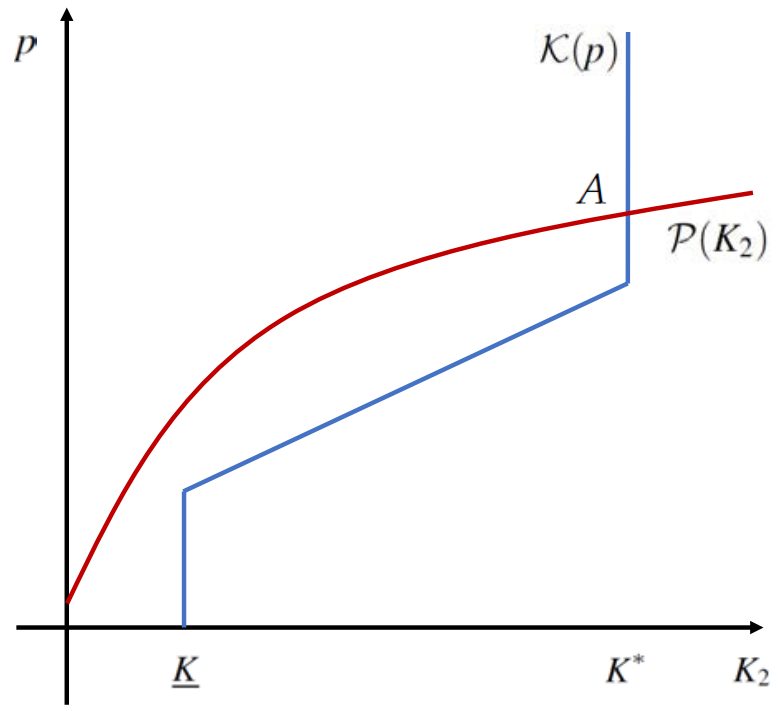

(a) Unique continuation equilibrium

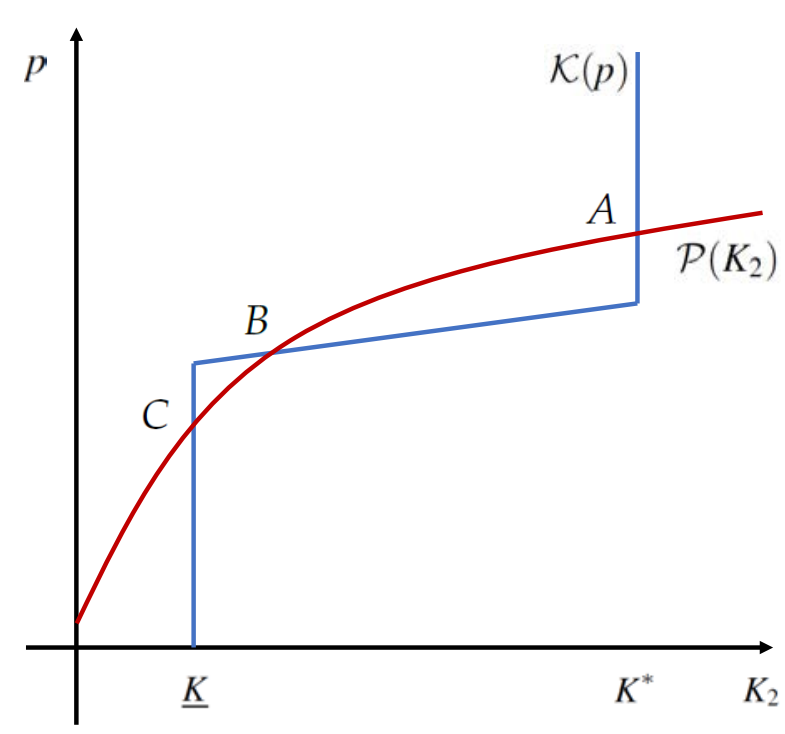

(b) Multiple continuation equilibria

Figure 1: Continuation equilibria

binds. From now on, whenever there are three equilibria as in panel (b), we will rule out the unstable intermediate equilibrium $B$ and focus on the two stable equilibria $A$ and $C$.

Equilibrium multiplicity comes from the positive feedback between banks' investment and the real exchange rate. In turn, this positive feedback is due to currency mismatch, namely, from the inequality $e_{b, 1}^{N}>b_{1}^{N}$. This makes it possible to have a self-fulfilling depreciation: a lower $p$ causes a reduction in banks' net worth; this causes lower investment, lower wages, and lower consumers' wealth; finally, this causes a low demand for nontradables, producing a lower equilibrium value of $p$.

Whenever multiple equilibria are possible, we interpret the "bad" equilibrium with low $p$ and $K_{2}$ as a financial crisis and obtain a number of predictions about the behavior of consumption, investment, the exchange rate, and the current account in a crisis.

Proposition 2. If there are three equilibria and we compare the two stable ones, we obtain the following predictions:

i. Investment and consumption are lower in the crisis equilibrium;

ii. The real exchange rate is more depreciated in the crisis equilibrium;

iii. The current account balance is higher in the crisis equilibrium;

iv. The utility of consumers is lower in the crisis equilibrium. If the following sufficient condition is satisfied,

$$
(1-\beta \theta) \phi^{\frac{1}{1-\alpha}}>\phi-\beta \theta
$$


the utility of bankers is also lower in the crisis equilibrium.

The improvement in the current account shows that the domestic banking crisis is associated with a capital flight. The capital flight has a double nature: the contraction in investment is driven by the reduction in banks' net worth, while the contraction in consumption is driven by lower future wages. The recent literature includes papers that emphasize financial constraints (Mendoza, 2010) and lower future income growth (Aguiar and Gopinath, 2007) as causes of capital account reversals in emerging markets. Here both mechanisms are active.

The proposition shows that the equilibria are Pareto ranked, as both households and bankers get lower utility in the crisis equilibrium. ${ }^{12}$ On the households' side, welfare is lower because of lower capital accumulation and hence lower future real wages. On the bankers' side, the effects are subtler because the rate of return on banks' net worth is actually higher in the low- $p$ equilibrium. However, net worth itself is lower. The proposition gives a sufficient condition under which the latter effect dominates.

\subsection{Debt denomination and financial instability}

What is the role of debt denomination in exposing the economy to equilibrium multiplicity?

Proposition 1 shows that to have multiple equilibria there must exist an equilibrium in which the inferior technology is employed, $K_{2}=\underline{K}$. The existence of such equilibrium requires the following inequality to hold:

$$
\underline{K}>\frac{1}{1-\beta \theta}\left[\alpha K_{1}^{\alpha}-b_{1}^{T}+\mathcal{P}(\underline{K})\left(e_{b, 1}^{N}-b_{1}^{N}\right)\right] .
$$

The other two equilibria are present if and only if the following condition is also satisfied:

$$
K_{2}<\frac{1}{1-\beta \theta}\left[\alpha K_{1}^{\alpha}-b_{1}^{T}+\mathcal{P}\left(K_{2}\right)\left(e_{b, 1}^{N}-b_{1}^{N}\right)\right]
$$

for some $K_{2} \in\left(\underline{K}, K^{*}\right]$. The last two conditions thus provide necessary and sufficient conditions for the existence of three continuation equilibria.

Panel (a) of Figure 2 helps us to understand these conditions in the simple case in which (13) is satisfied at $K^{*}$. Inequality (12) requires that banks have insufficient net worth to buy the capital stock $\underline{K}$ when the exchange rate is $\underline{p}=\mathcal{P}(\underline{K})$, so that the inferior technology

\footnotetext{
${ }^{12}$ International investors are indifferent between the two equilibria as in both cases they get zero surplus from trading tradable-denominated bonds.
} 


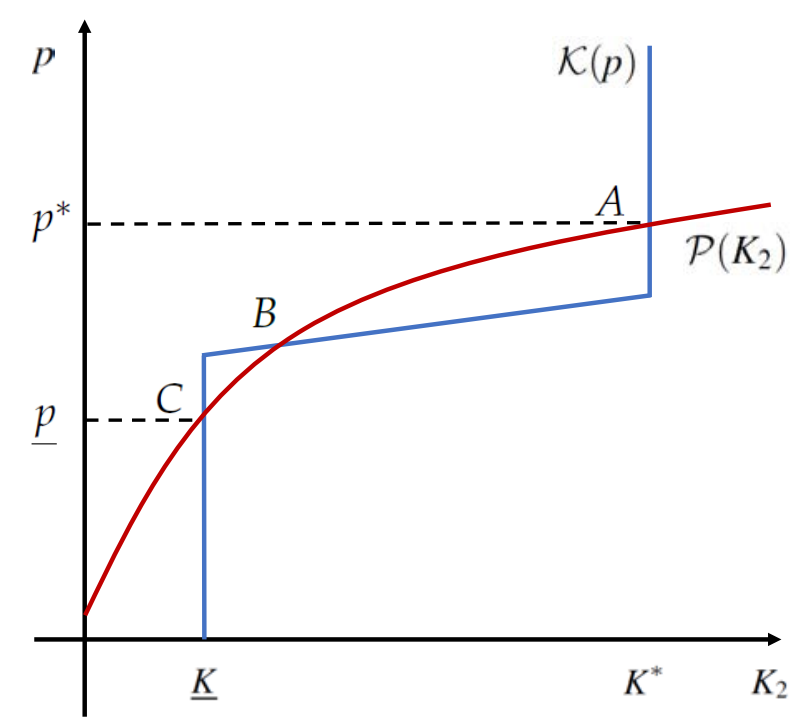

(a) Conditions for equilibrium multiplicity

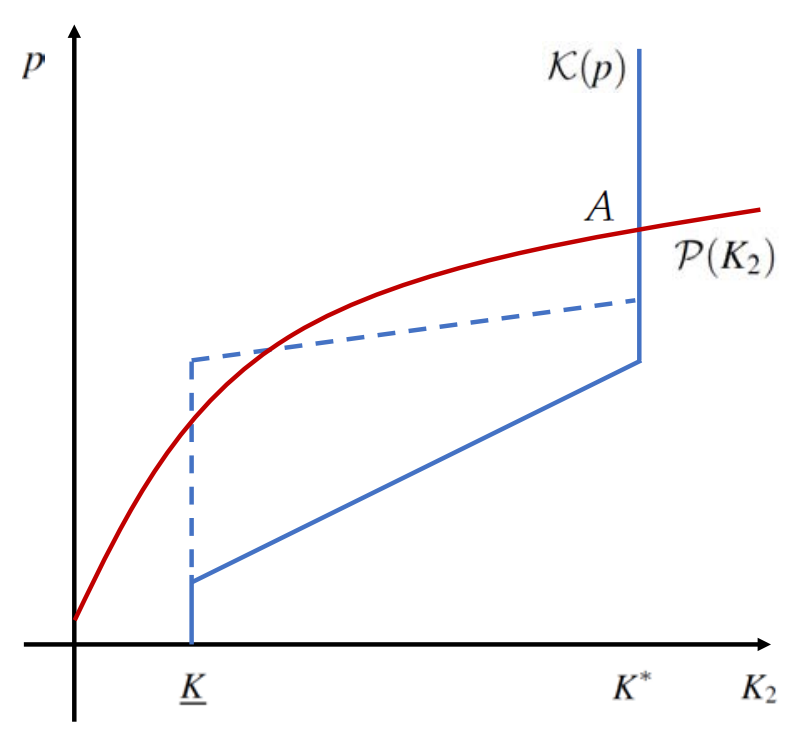

(b) The role of $N$-debt

Figure 2: Debt denomination and multiple equilibria

is employed. Inequality (13) at $K^{*}$ requires that at the appreciated exchange rate $p^{*}=$ $\mathcal{P}\left(K^{*}\right)$, banks have enough net worth to finance the first-best capital level $K^{*}$. Given that $K^{*}>\underline{K}$, in order for both conditions to be satisfied, we need the balance sheet effects of the appreciation to be sufficiently strong, which can only be the case if $e_{b, 1}^{N}-b_{1}^{N}$ is large enough. In particular, it is immediate to see that both conditions can never be satisfied if $e_{b, 1}^{N}=b_{1}^{N}$. In that case, the $\mathcal{K}$ schedule is a vertical line and multiplicity is impossible.

To further illustrate this idea, panel (b) of Figure 2 shows what happens if we start from the economy in panel (a) and we reduce $b_{1}^{T}$ and increase $b_{1}^{N}$ while leaving the value of total bank debt unchanged at the good equilibrium (that is, keeping constant $\left.b_{1}^{T}+\mathcal{P}\left(K^{*}\right) b_{1}^{N}\right)$. Since the bank net exposure is lower, the schedule $\mathcal{K}$ shifts downward for all $K_{2}<K^{*}$, and, for $b_{1}^{N}$ large enough, the bad equilibrium disappears.

Since mismatch is crucial for the presence of multiplicity, our next question is: why would banks choose a liability composition at date 0 that exposes them to crises with positive probability at date 1 ? This is the question we address in the next section.

\section{Dollarization}

We now go back to date 0 and study the equilibrium determination of banks' and consumers' assets and liabilities. Our main objective is to show that even though banks can choose ex ante whether to denominate their debt in tradables or non-tradables, this does not 
rule out the possibility of multiple continuation equilibria. That is, even though currency mismatch in banks' balance sheets opens the door to "bad" Pareto-dominated equilibria, banks do not necessarily have sufficient ex ante incentives to reduce their exchange rate exposure.

From now on, whenever we say an "equilibrium" of the model, we are referring to an equilibrium of the whole three-period model, as opposed to a continuation equilibrium that starts in period 1. We will use the following terminology. We say that an equilibrium is "fragile" if it features multiple continuation equilibria that happen with positive probability at $t=1$. We say that an equilibrium is "safe" if the equilibrium values of $\left\{a_{1}^{T}, a_{1}^{N}, b_{1}^{T}, b_{1}^{N}, K_{1}\right\}$ are such that there is a unique continuation equilibrium. Notice that the requirement for a safe equilibrium is not just that a single continuation equilibrium is selected with probability 1 at $t=1$, but also that no other continuation equilibrium exists.

Our argument in this section is constructive. First, we show how to construct examples of fragile equilibria. Second, we show that given an economy with a fragile equilibrium, the same economy also admits a safe equilibrium and we compare the two equilibria. At the end of this section, we use a numerical example to illustrate our argument and provide intuition. Readers less interested in the formal steps can skip directly to the example.

\subsection{Portfolio choice}

Consider first the portfolio decision problem of consumers and banks at date 0 . Consumers' optimization gives the following first-order conditions for $a_{1}^{T}$ and $a_{1}^{N}$ :

$$
q_{0}^{T} \lambda_{c, 0}=\beta \mathbb{E}\left[\lambda_{c, 1}\right], \quad q_{0}^{N} \lambda_{c, 0}=\beta \mathbb{E}\left[\frac{p_{1}}{p_{0}} \lambda_{c, 1}\right]
$$

where

$$
\lambda_{c, t}=\left(c_{t}^{T}\right)^{\omega(1-\gamma)-1}
$$

is the consumers' marginal utility of wealth (in tradables).

On the banks' side, we will focus on cases in which the collateral constraint is slack at time 0 . The banks' first-order conditions for $b_{1}^{T}$ and $b_{1}^{N}$ then take a similar form:

$$
q_{0}^{T} \lambda_{b, 0}=\mathbb{E}\left[\lambda_{b, 1}\right], \quad q_{0}^{N} \lambda_{b, 0}=\mathbb{E}\left[\frac{p_{1}}{p_{0}} \lambda_{b, 1}\right]
$$


and the bankers' marginal utility of wealth at $t=1$ is

$$
\lambda_{b, 1}=\frac{r_{2}-\theta}{1-\beta \theta}
$$

To interpret the last expression notice that a unit of net worth can be levered to purchase $1 /(1-\beta \theta)$ units of capital at $t=1$. And the payoff per unit of capital at $t=2$, net of debt repayments, is $r_{2}-\theta$. So we get a return of $\left(r_{2}-\theta\right) /(1-\beta \theta)$ per unit of net worth. ${ }^{13}$

It is useful to remark that when multiple equilibria are possible, the bankers' marginal utility of wealth is higher in the bad equilibrium, since in that equilibrium capital is scarcer and yields a higher rate of return. Therefore, even though bankers are risk neutral, they still perceive a high marginal utility of wealth in states of the world in which their net worth is low. This is a hedging motive that commonly arises in general equilibrium models with financial constraints, as pointed out, for example, in Rampini and Viswanathan (2010).

\subsection{Fragile equilibrium}

Take a vector of date 1 initial positions $\left\{a_{1}^{T}, a_{1}^{N}, b_{1}^{T}, b_{1}^{N}, K_{1}\right\}$ such that multiple continuation equilibria are possible. Suppose now that we want to construct an equilibrium in which the two stable continuation equilibria occur with positive probability. Given that the price $p_{1}$ is different in the two equilibria and there are only two states of the world at $t=1,{ }^{14}$ domestic consumers and bankers have sufficient instruments to achieve perfect risk sharing among themselves. This means that the portfolio conditions derived above can be satisfied if and only if the marginal utilities of wealth of consumers and bankers are equalized across states of the world, using the appropriate Pareto weights. That is, the portfolio conditions can be satisfied if and only if there is a $\Phi>0$ such that

$$
\left(c_{1}^{T}\right)^{\omega(1-\gamma)-1}=\Phi \beta \frac{r_{2}-\theta}{1-\beta \theta}
$$

in both the good and the continuation equilibria.

Can we construct an equilibrium in which the last condition is satisfied? The answer is yes because both the consumers' and the bankers' marginal utilities of wealth are higher if the bad equilibrium is realized. Building on this intuition, the next proposition shows how to construct a fragile equilibrium and what conditions are required for the construction.

\footnotetext{
${ }^{13}$ The expression is also valid if $r_{2}=1 / \beta$ and banks are unconstrained. Then the expression boils down to $\lambda_{b, t}=1 / \beta$, as the return per unit of net worth is simply the interest rate $1 / \beta$.

${ }^{14}$ To be precise, there are only two payoff-relevant states. The sunspot is a continuous variable, but it can only select one of the two stable continuation equilibria.
} 
For simplicity, we focus on constructing fragile equilibria in which non-tradable positions are exactly zero and in which, as mentioned above, the collateral constraint is slack in period 0 , so $K_{1}=K^{*}$. We use the superscripts $G$ and $B$ to denote variables in the good and bad continuation equilibria.

Proposition 3. Fix all the model parameters except $\gamma$ and the initial asset positions at $t=0$. Take a vector of date 1 initial positions $\left\{a_{1}^{T}, a_{1}^{N}, b_{1}^{T}, b_{1}^{N}, K_{1}\right\}$, with

$$
a_{1}^{N}=b_{1}^{N}=0, \quad K_{1}=K^{*}, \quad b_{1}^{T} \leq \theta K_{1} .
$$

Suppose that, given these positions, there are two continuation equilibria that satisfy

$$
\left(\frac{w_{1}+\beta w_{2}^{B}+a_{1}^{T}}{w_{1}+\beta w_{2}^{G}+a_{1}^{T}}\right)^{\omega-1}<\frac{r_{2}^{B}-\theta}{r_{2}^{G}-\theta} .
$$

Then there exist a coefficient of relative risk aversion $\gamma$ and date 0 initial positions $\left\{a_{0}^{T}, a_{0}^{N}, b_{0}^{T}, b_{0}^{N}, K_{0}\right\}$ that generate a fragile equilibrium in which the two continuation equilibria above are realized with positive probability.

The proof of this proposition relies on the fact that continuation equilibria can be constructed independently of the parameter $\gamma$, as the schedules $\mathcal{P}$ and $\mathcal{K}$ do not depend on that parameter. Then $\gamma$ can be chosen to ensure that the two continuation equilibria are consistent with ex ante optimality. The role of condition (15) is discussed in the proof of the proposition in the appendix.

Proposition 3 relies on making the consumers sufficiently risk averse to match the bankers' hedging motive. This logic can also be turned around, and we can show that if consumers' risk aversion is low enough, then the economy cannot feature a fragile equilibrium. The next proposition provides a uniqueness result along these lines.

Proposition 4. Suppose consumers' risk aversion satisfies

$$
\gamma<1+\frac{\beta(1-\alpha)-(\phi-\beta \theta)}{\omega(\phi-\beta \theta)} .
$$

Then there exists no fragile equilibrium with $a_{1}^{T} \geq 0$. 


\subsection{Safe equilibrium}

Suppose we have constructed an example of an economy that has a fragile equilibrium following the steps in Proposition 3. We can then ask whether the same economy also admits a safe equilibrium. The next proposition shows that the answer is yes.

Proposition 5. Take an economy with a fragile equilibrium constructed as in Proposition 3. The economy also has a safe equilibrium. Comparing the safe and the fragile equilibria, $c_{0}$ and $p_{0}$ are higher and the trade balance is lower in the safe equilibrium.

The idea behind this proposition is to take the good continuation equilibrium that is part of the fragile equilibrium under consideration and rearrange the debt composition of the bankers in favor of non-tradable debt in order to reduce the currency mismatch in their balance sheet. The logic of Figure 2 suggests that this eventually eliminates the multiplicity while leaving total repayments in the good equilibrium unchanged. Because of market clearing, this requires an increase in the consumers positions in non-tradable denominated bonds, as market clearing requires $b_{1}^{N}=a_{1}^{N}$. This can always be done because consumers are no longer worried about denominating their saving in non-tradables once the bad equilibrium is eliminated, as the depreciation risk associated with the crisis disappears.

The proposition states that the safe equilibrium has higher consumption and a more appreciated real exchange rate than the fragile equilibrium. This happens because consumers at $t=0$ are no longer concerned about the bad equilibrium outcome, and this reduces their incentives to save. As they choose higher consumption at $t=0$, their demand for non-tradables increase, and this pushes up the real exchange rate. The time $t=0$ choice of capital is, however, the same in the two equilibria. Because of full depreciation and inelastic labor, the marginal product of capital at date $t=1$ is state uncontingent, which implies that its rate of return is equalized to the rate of return on a bond denominated in tradable goods. This result follows from the fact that the rate of return equals $1 / \beta$ in both the safe and the fragile equilibria.

\subsection{A numerical example}

We now present a simple numerical example of an economy that admits both safe and fragile equilibria. Table 1 reports the parameters used and several statistics of interest in the two equilibria.

To interpret the forces at work in the two equilibria, it is useful to introduce a standard asset pricing condition that relates the interest rates on tradable and non-tradable denomi- 
Table 1: Safe and fragile equilibria: a numerical example

\begin{tabular}{lcc}
\hline \hline & Safe & Fragile \\
\hline$a_{1}^{N}, b_{1}^{N}$ & 0.40 & 0.00 \\
$a_{1}^{T}$ & 0.01 & 0.17 \\
$b_{1}^{T}$ & 0.16 & 0.46 \\
St. dev. of $\log w_{2}$ & 0.00 & 0.07 \\
St. dev. of $\log p_{1}$ & 0.00 & 0.025 \\
Covar. of $\log w_{2}$ and $\log p_{1}$ & 0.00 & 0.002 \\
$\mathbb{E}\left[\left(1+i_{0}^{N}\right)\left(p_{1} / p_{0}\right)\right]$ & 1.01 & 1.06 \\
$\left(1+i_{0}^{T}\right)$ & 1.01 & 1.01 \\
\hline
\end{tabular}

Notes: The parameters used in the example are: $\alpha=0.40, \beta=0.99, \omega=0.20, e_{c, t}^{N}=0.20, e_{c, t}^{N}=0.40, \theta=0.77$, $\phi=1.40, \gamma=55.48$. The initial conditions are $K_{0}=0.21, a_{0}^{T}=0.23, b_{0}^{T}=0.95, a_{0}^{N}=b_{0}^{N}=0.00$.

nated bonds $1+i_{0}^{T}=1 / q_{0}^{T}$ and $1+i_{0}^{N}=1 / q_{0}^{N} \cdot{ }^{15}$

$$
1+i_{0}^{T}-\left(1+i_{0}^{N}\right) \mathbb{E}\left[\frac{p_{1}}{p_{0}}\right]=\operatorname{Cov}\left(\left(1+i_{0}^{N}\right) \frac{p_{1}}{p_{0}}, \frac{\lambda_{c, 1}}{\mathbb{E}\left[\lambda_{c, 1}\right]}\right)
$$

where $\lambda_{c, 1}$ is the consumers' marginal utility of wealth. The left-hand side of equation (16) can be interpreted as a standard uncovered interest rate parity (UIP) relation, which compares the returns of bonds denominated in different units.

In the safe equilibrium, consumers decide to denominate most of their savings in nontradables. Banks absorb the desired pesos savings of consumers and issue tradable bonds to finance any further shortfall between desired investment and their initial net worth. Because most of the banks' liabilities are denominated in non-tradables, the banks have little currency mismatch on their balance sheets. Indeed, in our example there is no mismatch at all $\left(b_{1}^{N}=e_{b, 1}^{N}\right)$, and the economy has only a unique stable continuation equilibrium at date $t=1$. This can be appreciated from the fact that consumers' wages and the real exchange rate are not stochastic.

Why are these $t=0$ asset choices optimal from the perspective of consumers and banks? The impossibility of the bad equilibrium at date $t=1$ means that agents in the economy do not face any risk. Thus, the two bonds are perfect substitutes as their interest rate is equalized. In equilibrium, this is precisely what happens because of equation (16). It follows that in the safe equilibrium, both consumers and banks are indifferent about the denomination of their assets and liabilities, which rationalizes these positions.

\footnotetext{
${ }^{15}$ This condition can be derived by following standard steps from the optimality conditions (14).
} 
In the fragile equilibrium, consumers decide to denominate their savings in tradable goods $\left(a_{1}^{*}=0.17, a_{1}^{N}=0.00\right)$. Banks have little access to pesos, and they finance their date $t=0$ operations by issuing debt denominated in tradable goods. This balance sheet of the banks generates currency mismatch $\left(e_{b, 1}^{N}>b_{1}^{N}\right)$, and it exposes the economy to a bad equilibrium at date $t=1$.

The risk of a bad equilibrium at date $t=1$ is what justifies the portfolio choices of agents in the economy at date $t=0$. From Table 1 , we can verify that consumers' lifetime income is exposed to the realization of the sunspot at date $t=1$. Importantly, the real exchange rate depreciates when a crisis occurs, generating a negative comovement between consumers' income and the real exchange rate. This property of the exchange rate makes bonds denominated in tradable goods a "crisis hedge" for consumers, and this justifies their decision to denominate their savings in tradables at $t=0$. The precautionary motive of the households is met, in equilibrium, by a riskier balance sheet of the banks, which is ultimately what exposes the economy to financial instability.

Why are banks happy to borrow in tradables and be exposed to exchange rate risk? The answer is that borrowing in tradables is "cheaper" for banks. This can be seen by comparing the interest rates of the two bonds. From Table 1, we can see that in the fragile equilibrium, the rate of return on bonds denominated in tradables is lower than the one on non-tradables. This deviation from the UIP condition is effectively a result of the consumers' unwillingness to save in non-tradables, which in equilibrium bids up the interest rate on these bonds. Paradoxically, this behavior generates in equilibrium the very risk against which the consumers are trying to insure.

Before continuing, it is useful to further discuss properties of safe and fragile equilibria. As for the safe equilibrium, we have seen that consumers and banks are indifferent over their asset positions at $t=0$. Because of that, the split between tradable and non-tradable bonds on the balance sheets of domestic agents is indeterminate, and there is a continuum of safe equilibria. This is due to the absence of fundamental shocks, which implies that the safe equilibrium is deterministic.

As for the fragile equilibrium, it is worth emphasizing that a key assumption underlying its existence is the presence of segmentation in financial markets. The segmentation has both an international and a domestic dimension.

At the international level, it is important that some mechanism prevents foreign investors from issuing non-tradable denominated bonds to the local banks. To understand why, consider the fragile equilibrium in Table 1 and suppose that we allow foreign investors to purchase claims denominated in non-tradables. Because foreign investors are risk neutral, they have an incentive at date $t=0$ to purchase those claims: due to the UIP deviation, 
they earn a positive excess return from this strategy. Eventually, this force would eliminate the fragile equilibrium because, by issuing non-tradable denominated claims, the balance sheets of local banks become less exposed to exchange rate fluctuations. Importantly, this argument works only because foreign investors are risk neutral and have deep pocketsassumptions that generate an infinitely elastic supply of funds. There is ample empirical evidence, however, that the supply of foreign capital to emerging market economies is not perfectly elastic. ${ }^{16}$ In our paper, we consider the extreme view in which the supply of foreign funds in "local currency" (non-tradables) is perfectly inelastic, but this is just a useful simplification. Our results would not be qualitatively different if we were to relax this assumption and instead model foreign lenders as risk-averse specialists that are not diversified toward the small open economy.

At the domestic level, we have assumed that the bankers and the consumers are distinct agents. This assumption, shared by recent papers such as Brunnermeier and Sannikov (2014) and He and Krishnamurthy (2012), allows us to consider parametrizations in which the consumers are relatively more risk averse than the bankers, which, from Proposition 4 , is important in obtaining the fragile equilibrium. More primitive frictions that limit the participation of consumers to asset markets would offer a justification for our assumption.

\section{Lending of last resort}

After having characterized the sources of financial instability in this economy, we turn to government intervention. In this section, we add to our model a benevolent government that intervenes in financial markets at $t=1$. We then study continuation equilibria and find under what conditions government intervention can or cannot eliminate multiplicity. In the next section, we move back to date 0 to analyze the portfolio choice of the government and how it interacts with the private sector's portfolio choice.

\subsection{Modeling interventions and limited fiscal capacity}

At date 1 the government can make a transfer $T_{b}$ to banks in exchange for a repayment $R$ at date $2 .{ }^{17}$ The government finances the transfer $T_{b}$ by raising linear labor income taxes on consumers and by borrowing against labor income taxes to be raised at $t=2$ and against the repayment $R$. Letting $\tau_{t}$ denote the labor income tax rate, $T_{t} \geq 0$ a lump-sum transfer

\footnotetext{
${ }^{16}$ For example, Borri and Verdhelan (2013) and Tourre (2017) document large risk premia in emerging markets' sovereign bonds, while Du and Schreger (2016) and Maggiori, Nieman, and Schreger (2017) recently document the dominance of dollar denomination in cross-border flows.

${ }^{17}$ To simplify, we assume that all financial transactions from $t=1$ onward are in tradables.
} 
to consumers, and $A_{2}^{T}$ the government's net bond position in tradables, the government budget constraints at $t=1,2$ are

$$
\begin{aligned}
T_{b}+T_{1} & \leq \tau_{1} w_{1}-\beta A_{2}^{T}, \\
-A_{2}^{T}+T_{2} & \leq \tau_{2} w_{2}+R .
\end{aligned}
$$

We make two assumptions that limit the government's ability to intervene.

First, we assume that the government has no superior ability to enforce repayments from banks at $t=2$, so total repayments to the private sector and to the government must satisfy the collateral constraint

$$
b_{2}^{T}+R \leq \theta k_{2}
$$

Second, we assume limited fiscal capacity by imposing a limit on the government's ability to raise labor taxes:

$$
\tau_{t} \leq \xi
$$

In the Online Appendix, we provide a microfoundation for this assumption by introducing an informal sector, completely shielded from taxation, that employs labor and capital and in which labor is less efficient by a factor $1-\xi$. We then show that constraint (17) needs to be satisfied to prevent labor and capital from switching to the informal sector.

To make the analysis interesting, we assume that at date 0 , absent government intervention, the economy is in a fragile equilibrium in which crises occur with positive probability. Moreover, we assume that the capital stock is at its first-best level $K^{*}$ in the good continuation equilibrium.

As in the case of no intervention, tradable consumption is constant in equilibrium, $c_{1}^{T}=$ $c_{2}^{T}=c^{T}$, and non-tradable consumption is equal to the endowment, $c_{1}^{N}=c_{2}^{N}=e^{N}$. The government is benevolent, and its objective is to maximize the social welfare function

$$
(1+\beta) U\left(c^{T}, e^{N}\right)+\Phi \beta c_{b}^{T}
$$

where $c_{b}^{T}$ denotes the consumption of the banker at $t=2$. In order to focus on the role of the government as a lender of last resort, we set the Pareto weight to $\Phi=U_{c^{T}}\left(c^{T, G}, e^{N}\right)$, where $c^{T, G}$ is consumption in the good continuation equilibrium with no government intervention. This social welfare function implies that the government does not want to redistribute resources between bankers and consumers under the allocations prevailing in the good continuation equilibrium. Because of complete financial markets at date 0 , this also implies that the government has no redistributive motives in the bad continuation equilibrium. 


\subsection{Timing and equilibrium}

We now specify the timing of actions by private agents and the government at $t=1$. We split date 1 into two subperiods:

i. In the first subperiod, consumers buy non-tradable goods and the non-tradable goods market clears at the price

$$
p_{1}=\frac{1-\omega}{\omega} \frac{c^{T, e}}{e^{N}}
$$

where $c^{T, e}$ denotes the private sector's expectation of tradable consumption. In the same subperiod, consumers and international investors buy bonds issued by the government, subject to the borrowing limit

$$
-A_{2}^{T} \leq \xi w_{2}^{e}+R^{e} \equiv-\underline{A},
$$

where $w_{2}^{e}$ and $R^{e}$ denote the private sector's expectation of wages and banks' repayments to the government in period 2.

ii. In the second subperiod, the government chooses $T_{b}, R, \tau_{1}$, and $T_{1}$. Banks buy capital using their own net worth, the government transfer, and funds borrowed from consumers and international investors. Consumers choose their financial position $a_{2}^{T}$ and their tradable consumption.

In the Online Appendix, we show that the government's problem in subperiod (ii) is equivalent to the problem of choosing an allocation $\left\{c^{T}, c_{b}^{T}, k_{2}, K_{2}\right\}$ that maximizes social welfare (18) subject to the constraints

$$
\begin{aligned}
(1+\beta) c^{T}+\beta c_{b}^{T} & \leq a_{1}^{T}-b_{1}^{T}+K_{1}^{\alpha}+\beta K_{2}^{\alpha}-k_{2}-\phi\left(K_{2}-k_{2}\right) \\
c_{b}^{T} & \geq \alpha K_{2}^{\alpha-1} k_{2}-\theta k_{2} \\
\alpha \beta K_{2}^{\alpha-1} & \geq \phi \text { and } K_{2}-k_{2} \geq 0 \\
\min \left\{\frac{n_{1}}{1-\beta \theta}, K^{*}\right\} & \leq k_{2} \leq \min \left\{\frac{M}{1-\beta \theta}, K^{*}\right\}
\end{aligned}
$$

with at least one condition in (21) holding as an equality. The variable $M$ in equation (22) is defined as follows:

$$
M=n_{1}+\xi w_{1}-\beta \underline{A} .
$$

Constraint (19) is the intertemporal resource constraint. Constraint (20) is the bankers' participation constraint and reflects the assumption that the government has no superior enforcement capacity. The constraints in (21) and their complementary slackness condition 
ensure optimality in the inferior technology sector. Finally, the constraints in (22) define a feasible interval for $k_{2}$. The first constraint requires that $k_{2}$ not be smaller than the level that banks would choose with $T_{b}=0$ and comes from the non-negativity of $T_{b}$. The second constraint comes from the assumption of limited fiscal capacity and puts an upper bound on banks' investment in period 1, which depends on the banks' net worth and the maximum transfer that the government can make. An important consequence of our timing assumptions is that the government takes both $n_{1}$ and $M$ as given in the problem just described.

This characterization allows us to define a continuation equilibrium in a compact way.

Definition 2. The vector

$$
\left\{c^{T}, c_{b}^{T}, k_{2}, K_{2}, n_{1}, M, p_{1}\right\}
$$

is a continuation equilibrium with government intervention if and only if:

$i$. The allocation $\left\{c^{T}, c_{b}^{T}, k_{2}, K_{2}\right\}$ maximizes the government objective (18) subject to the constraints (19)-(22), taking as given $\left\{n_{1}, M\right\}$.

ii. $\left\{n_{1}, M\right\}$ are consistent with rational expectations and market clearing in the non-tradable market, that is,

$$
\begin{aligned}
& n_{1}=\alpha K_{1}^{\alpha}-b_{1}^{T}+p_{1}\left(e_{b, 1}^{N}-b_{1}^{N}\right), \\
& M=n_{1}+\xi(1-\alpha) K_{1}^{\alpha}+\beta \xi(1-\alpha) K_{2}^{\alpha},
\end{aligned}
$$

where

$$
p_{1}=\frac{1-\omega}{\omega} \frac{c^{T}}{e^{N}}
$$

\subsection{Fiscal capacity and lending of last resort}

We now characterize equilibria, proceeding in two steps. First, we study the government's best response. That is, we study how the solution of the government's decision problem varies with $n_{1}$ and $M$. Second, we characterize equilibria by imposing the fixed point conditions (23)-(24). The next proposition characterizes the government's best response.

Proposition 6. There exists a threshold $\hat{M}>\underline{K}(1-\beta \theta)$ such that:

1. If $M<\hat{M}$ and $k_{2}^{B} \in\left[\frac{n_{1}}{1-\beta \theta}, \frac{M}{1-\beta \theta}\right]$, the government's optimal policy replicates the bad equilibrium allocation, $c^{T}=c^{T, B}, c_{b}^{T}=c_{b}^{T, B}, k_{2}=k_{2}^{B}$, and $K_{2}=\underline{K}$. 
2. If $M \geq \hat{M}$, the government's optimal policy sets

$$
\begin{aligned}
k_{2} & =K_{2}=\min \left\{\frac{M}{1-\beta \theta}, K^{*}\right\}, \\
c^{T} & =\min \left\{\frac{1}{1+\beta}\left(a_{1}^{T}-b_{1}^{T}+K_{1}^{\alpha}+\beta(1-\alpha) K_{2}^{\alpha}-(1-\beta \theta) K_{2}\right), c^{T, G}\right\}, \\
c_{b}^{T} & =\frac{1}{\beta}\left(a_{1}^{T}-b_{1}^{T}+K_{1}^{\alpha}+\beta K_{2}^{\alpha}-K_{2}-(1+\beta) c^{T}\right) .
\end{aligned}
$$

Let us first sketch the formal argument for the proposition and then turn to intuition. In Figure 3 we plot the government's objective as a function of $k_{2}$, choosing all other variables optimally and ignoring the constraints in (22). To solve the government's problem, we maximize this function, choosing $k_{2}$ in the feasible interval defined by (22). The function has two local maxima: one at $k^{B}$ in the region $k_{2}<\underline{K}$ and one at $K^{*}$ in the region $k_{2} \geq \underline{K}$. This non-concavity is a general property derived formally in the proof of the proposition (in the appendix). To define the cutoff $\hat{M}$, we look for the $k_{2}=\hat{M} /(1-\beta \theta)$ that is the lowest point in the region $k_{2} \geq \underline{K}$ that yields the same payoff as the local maximum in the region $k_{2}<\underline{K}$. This construction is illustrated in panel (a) of Figure 3. Result (1) in the proposition considers the case $M \leq \hat{M}$. In this case, the local maximum at $k^{B}$ is also a global maximum. Result (2) considers the case $M>\hat{M}$. In this case, the global maximum is in the region $k_{2} \geq \underline{K}$.

Turning to intuition, let us first understand why there is a local maximum at the bad equilibrium investment level $k_{2}^{B}$. Suppose we start at the bad equilibrium and the government transfers a dollar to the banks by taxing consumers. Since the collateral constraint is binding, banks increase $k_{2}$ by $d k_{2}=1 /(1-\beta \theta)$. Total investment $K_{2}$ is unaffected, so wages are constant. The present value of total resources increases by $(\phi-1) d k_{2}$ because the production technology of the banks is more efficient than the inferior technology. The bankers' participation constraint (20) requires that bankers' consumption satisfies

$$
\beta d c_{b}^{T}=\beta\left(r_{2}-\theta\right) d k_{2}=\frac{r_{2}-\theta}{1-\beta \theta}
$$

and, using the intertemporal budget constraint and $\beta r_{2}=\phi$, it follows that

$$
(1+\beta) d c^{T}=(\phi-1) d k_{2}-\beta\left(r_{2}-\theta\right) d k_{2}=-(1-\beta \theta) d k_{2}=-1
$$




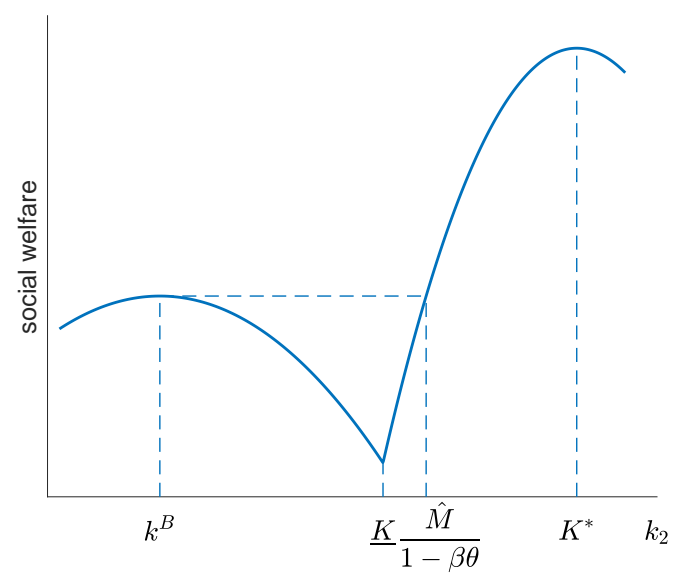

(a) Finding the cutoff $\hat{M}$

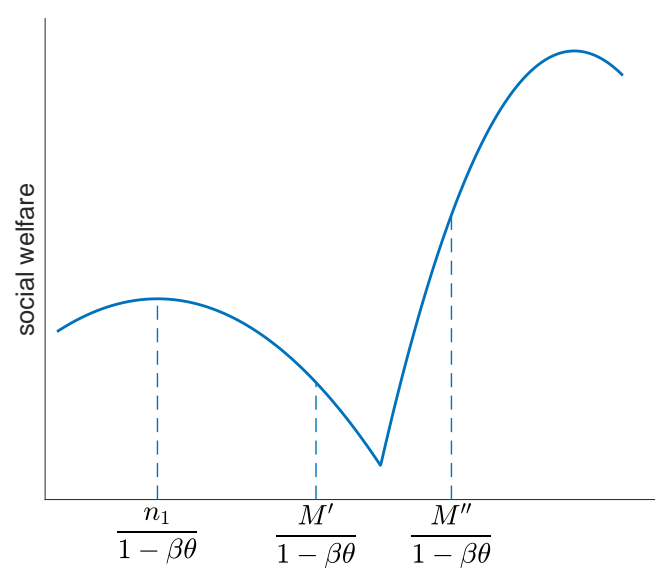

(b) Low and high fiscal capacity

Figure 3: Government optimization

The change in social welfare is then

$$
(1+\beta) U_{c^{T}}\left(c^{T}, e^{N}\right) d c^{T}+\Phi \beta d c_{b}^{T}=-U_{c^{T}}\left(c^{T}, e^{N}\right)+\Phi \beta \frac{r_{2}-\theta}{1-\beta \theta},
$$

which equals zero at the bad continuation equilibrium given our choice of Pareto weights. This shows that, in a neighborhood of the bad continuation equilibrium, the government has no incentive to support the banks. Consistently with this observation, the case $M=M^{\prime}$ shown in panel (b) of Figure 3 is an example in which fiscal capacity is low and the optimal policy is no intervention.

The government's marginal incentives are different in the region above $\underline{K}$. In that region, repeating the steps above, an additional dollar transfer to the banks changes social welfare by

$$
-U_{c^{T}}\left(c^{T}, e^{N}\right)+\Phi \beta \frac{r_{2}-\theta}{1-\beta \theta}+\beta\left(U_{c^{T}}\left(c^{T}, e^{N}\right)-\Phi\right) d w_{2}
$$

where $d w_{2}=\beta(1-\alpha) r_{2} /(1-\beta \theta)>0$. The first two terms are the same as before. The last term reflects a pecuniary externality that operates through the wage and is positive as long as $c^{T}$ is below its first-best level $c^{T, G}$. When $M$ is large enough, the marginal gains in the region above $\underline{K}$ more than offset the marginal losses in the region below $\underline{K}$, and the government's optimal response is to intervene. The case $M=M^{\prime \prime}$ in panel (b) of Figure 3 is an example in which fiscal capacity is high enough that the optimal policy is maximal intervention.

Notice the difference between private and social incentives. Private consumers could also be given the option to make a unilateral transfer to banks, but they would never choose to 
make it. The crucial difference between the government and individual consumers is that the government internalizes the general equilibrium effects of higher investment on wages. As the argument above shows, this is what makes intervention optimal.

Having studied the best response of the government, we can now characterize the equilibria in the model with government intervention.

Proposition 7. Let $M^{B}$ be

$$
M^{B}=n_{1}^{B}+\xi(1-\alpha) K_{1}^{\alpha}+\beta \xi(1-\alpha) \underline{K}^{\alpha}
$$

The economy with government intervention has a unique continuation equilibrium if and only if $M^{B}>\hat{M}$ and the allocation corresponds to the good continuation equilibrium with no government intervention. If $M^{B} \leq \hat{M}$, there are at least two stable continuation equilibria: one with $K_{2}=\underline{K}$ and one with $K_{2}=K^{*}$.

Let the functions $\mathcal{N}\left(M, n_{1}\right)$ and $\mathcal{M}\left(M, n_{1}\right)$ denote the values of $M$ and $n_{1}$ that come from (23)-(24) after substituting the government's optimal responses to $\left\{n_{1}, M\right\}$ on the right-hand side. An equilibrium corresponds to a fixed point of the function $\mathcal{N} \times \mathcal{M}$, that is a pair

$$
\left\{n_{1}, M\right\}=\left\{\mathcal{N}\left(M, n_{1}\right), \mathcal{M}\left(M, n_{1}\right)\right\} .
$$

Also, similar to the definition of $M^{B}$, let us define

$$
M^{G}=n_{1}^{G}+\xi(1-\alpha) K_{1}^{\alpha}+\beta \xi(1-\alpha)\left(K^{*}\right)^{\alpha}
$$

To illustrate Proposition 7 graphically, we plot $\mathcal{M}\left(M, n_{1}\right)$ in Figure 4 , fixing $n_{1}$ at its bad equilibrium level $n_{1}^{B}$. It is easy to show that $\mathcal{M}$ is non-decreasing in its first argument because Proposition 6 shows that a larger capacity to intervene leads the government to choose weakly higher levels for $K_{2}$ and $c^{T}$. Now two cases are possible. In panel (a) of the figure, we show the case $M^{B}<\hat{M}$. In this case, the bad equilibrium survives under government intervention because, under pessimistic expectations about future wages, the government has insufficient fiscal resources to intervene. And low investment validates the private sector's expectations by keeping future wages low. This is represented by point $C$ in the figure. At the same time, the good equilibrium (point $A$ in the figure) is also possible. To complete the argument for the existence of the good equilibrium, we just need to note that if the government chooses to intervene, the constraint $k_{2} \geq n_{1} /(1-\beta \theta)$ is not binding, so $\mathcal{M}\left(M^{G}, n_{1}^{G}\right)=\mathcal{M}\left(M^{G}, n_{1}^{B}\right)=M^{G}$.

In panel (b) of Figure 4 , we show the case $M^{B}>\hat{M}$. In this case, the bad equilibrium 


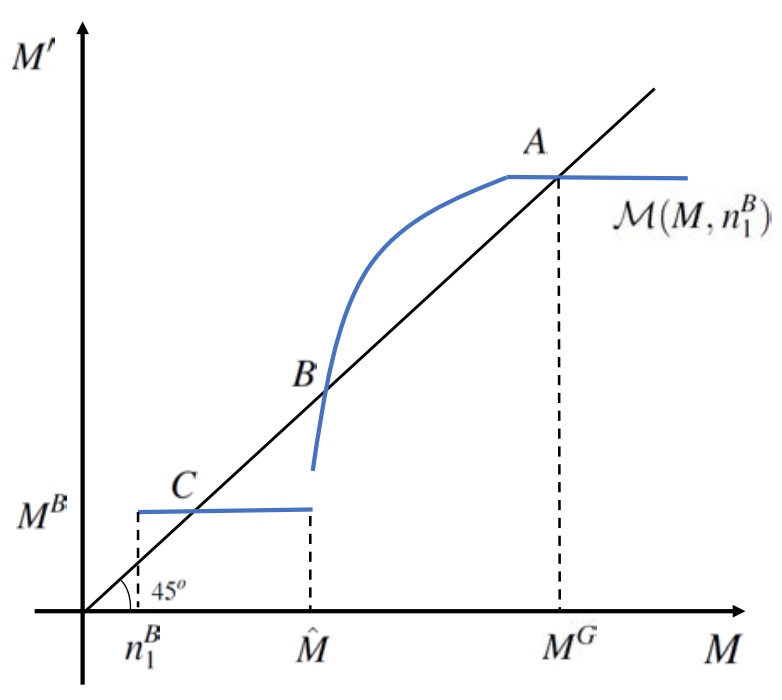

(a) Multiplicity

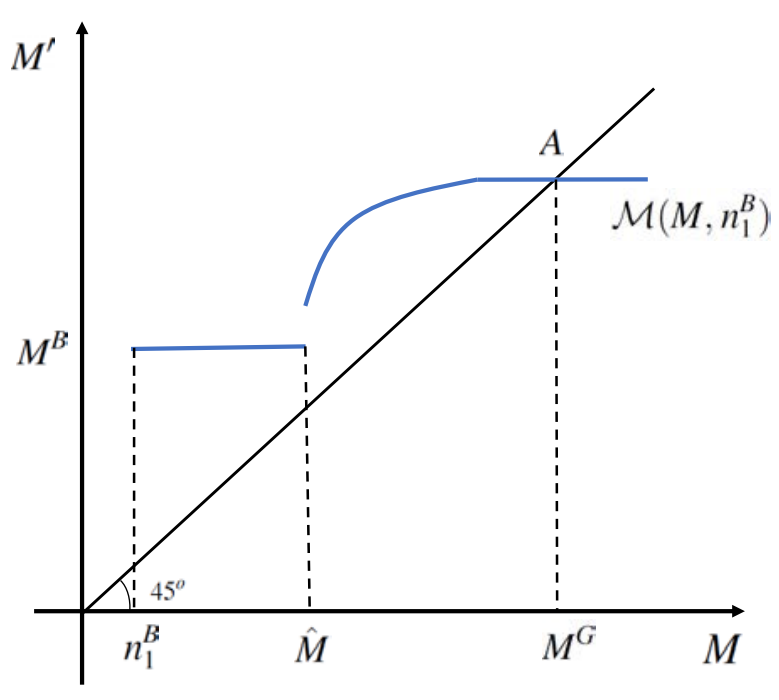

(b) Uniqueness

Figure 4: Equilibria with government intervention

of the economy with no intervention is ruled out because if we start there, the government has sufficient resources to move the economy to a better allocation. In fact, this condition is sufficient to rule out any equilibrium that does not correspond to the good equilibrium with no intervention. Again, the full argument relies on the fact that the value of $n_{1} /(1-\beta \theta)$ as a lower bound for $k_{2}$ is irrelevant if the government finds it optimal to intervene and go to the upper bound $M /(1-\beta \theta)$.

\subsection{Discussion}

Let us add a few remarks on the assumptions made in modeling government intervention.

First, in our simple model, the government has no incentive to intervene in a neighborhood of the bad equilibrium. This is a useful simplification that comes from the way we model the inferior technology. It is possible to enrich the model in order to make the decision problem of the government smoother, either by introducing richer tax distortions (e.g., via a labor supply margin) or by complicating our model of capital accumulation not financed by banks. This could eliminate the non-convexity in the government's problem and also make some level of intervention optimal in the bad equilibrium. The crucial thing is to have some force that makes the slope of the map $\mathcal{M}$ relatively low near the bad equilibrium, so that government intervention near the bad equilibrium is not powerful enough to push the economy to uniquely converge to the good equilibrium.

Second, let us discuss the role of our timing assumptions. Market clearing in the nontradable goods market and government borrowing happen in the first subperiod. This 
implies that the banks' net worth-which depends on $p_{1}$-and the government borrowing capacity are determined by consumers' expectations regarding future wages, which depend on their expectations about $K_{2}$. When the government intervenes in the second subperiod, the variables $n_{1}$ and $M$ have already been determined, so the government must take them as given even though its interventions will affect $K_{2}$. If the model featured the simultaneous determination of government policy and of $w_{2}^{e}$ and $p_{1}$, then it would be easy for the government to rule out multiplicity, as shown in the following result.

Proposition 8. Consider the model with government intervention, but assume that the actions in the first and second subperiods are simultaneous. Then, the government can uniquely implement the first-best allocation. This holds true even if $\xi=0$.

The logic for this result is that a successful lender of last resort is fully self-financed. If the government makes a large enough transfer to banks, investment goes up and future wage expectations increase, and this raises demand on the non-tradable market, leading to an appreciation. Then banks' net worth increases, allowing banks to finance the higher investment level and creating sufficient collateral to repay the government transfer in full. So if everything is simultaneous, the government can switch to the good equilibrium allocation by making a large enough transfer.

To meaningfully discuss the relation between fiscal capacity and lending of last resort, we need a model that breaks the simultaneity of Proposition 8. Our timing offers a simple way to break the simultaneity. An open area for future research is to explore richer dynamic specifications that capture more realistically the back and forth between government actions and market responses in this type of setup.

\section{The role of reserves}

We now consider the role of foreign currency reserves. To do so, we allow the government to take positions in tradable and non-tradable bonds at date 0 , so the government enters period 1 with an initial financial position $A_{1}^{T}+p_{1} A_{1}^{N}$. The analysis of the previous section can easily be extended to this case. However, in order to proceed, we need to make assumptions on how the economy responds at date 0 to the portfolio choices of the government. Here we consider two experiments.

First, we consider the case of unexpected interventions. That is, we assume the government buys the portfolio $\left(A_{1}^{T}, A_{1}^{N}\right)$ at date 0 , but the private sector does not expect the government to use these resources to intervene in financial markets. Second, we consider 
the case of fully anticipated interventions. That is, we assume that the private sector takes into account that the government will use its resources to intervene optimally at date 1 . Both exercises are useful in understanding how reserve accumulation affects the economy.

\subsection{Unexpected interventions}

In our first experiment, we assume that the private sector expects the government to simply transfer $A_{1}^{T}+p_{1} A_{1}^{N}$ back to the consumers at date 1 . This experiment shows how the portfolio $\left(A_{1}^{T}, A_{1}^{N}\right)$ changes the government's ability to credibly act as a lender of last resort.

For this experiment, we need to move in two steps. First, we characterize the equilibrium in which the government buys the portfolio $\left(A_{1}^{T}, A_{1}^{N}\right)$ at date 0 but does not intervene in financial markets at date 1 . This step gives us agents' portfolios at date 0 . Then, given these portfolios, we will study "off-equilibrium" optimal interventions at date 1.

Suppose we start at the fragile equilibrium of an economy with no government intervention and a zero government portfolio. If the government buys $\left(A_{1}^{T}, A_{1}^{N}\right)$ at date 0 and transfers the net return back to the consumers at date 1 , it is easy to see that there is still a fragile equilibrium, with values of $a_{1}^{T}+A_{1}^{T}$ and $a_{1}^{N}+A_{1}^{N}$ identical to those of the original equilibrium. All remaining quantities and prices are unchanged. This is a standard Ricardian equivalence result. The only thing we need to check, given that taxes are bounded by (17), is that the government has sufficient fiscal capacity to finance the net value of $\left(A_{1}^{T}, A_{1}^{N}\right)$ in all states of the world. We will take care of this requirement below.

We can then turn to the off-equilibrium analysis of interventions at date 1 . The analysis of the previous section can easily be extended to the case in which the government enters period 1 with a non-zero portfolio $\left(A_{1}^{T}, A_{1}^{N}\right)$. Only two things change. First, the definition of the total resources available to banks $M$ is now

$$
M=A_{1}^{T}+p_{1} A_{1}^{N}+n_{1}+\xi(1-\alpha) K_{1}^{\alpha}+\beta \xi(1-\alpha) K_{2}^{\alpha}
$$

Second, the resource constraint (19) in the government maximization problem becomes

$$
(1+\beta) c^{T}+\beta c_{b}^{T} \leq a_{1}^{T}+A_{1}^{T}-b_{1}^{T}+K_{1}^{\alpha}+\beta K_{2}^{\alpha}-k_{2}-\phi\left(K_{2}-k_{2}\right)
$$

However, we just made the argument that, in the case of unexpected interventions, the equilibrium value of $a_{1}^{T}+A_{1}^{T}$ will be the same as $a_{1}^{T}$ in the economy with a zero government portfolio. Therefore, the government maximization problem is unchanged.

The fact that the maximization problem of the government is unchanged implies that the cutoff $\hat{M}$ is equivalent to the case with $A_{1}^{T}=A_{1}^{N}$ studied in Proposition 6 . We can then 
derive the following result.

Proposition 9. Take an economy with a fragile equilibrium. Let $\hat{M}$ and $M^{B}$ be defined as in Propositions 6 and 7. Suppose the portfolio $\left(A_{1}^{T}, A_{1}^{N}\right)$ satisfies the inequalities

$$
\begin{aligned}
A_{1}^{T}+p_{1}^{B} A_{1}^{N} & >\hat{M}-M^{B}, \\
A_{1}^{T}+p_{1}^{G} A_{1}^{N} & >-\xi(1-\alpha)\left[K_{1}^{\alpha}+\beta\left(K^{*}\right)^{\alpha}\right], \\
q_{0}^{T} A_{1}^{T}+q_{0}^{N} A_{1}^{N} & <\beta \mathbb{E}\left[A_{1}^{T}+p_{1} A_{1}^{N}\right]+\xi(1-\alpha) \mathbb{E}\left[K_{0}^{\alpha}+\beta K_{1}^{\alpha}+\beta^{2} K_{2}^{\alpha}\right] .
\end{aligned}
$$

Then, given the positions $\left(A_{1}^{T}, A_{1}^{N}\right)$, the good equilibrium is the unique continuation equilibrium with government intervention.

To provide an interpretation of this result, consider the interesting case in which $M^{B}<$ $\hat{M}$, so optimal government intervention with $A_{1}^{T}=A_{1}^{N}=0$ is not sufficient to eliminate the bad equilibrium, as shown in Proposition 7.

Now suppose the government borrows in non-tradables to finance the accumulation of reserves denominated in tradables, taking positions $A_{1}^{T}>0>A_{1}^{N}$, and assume that these positions yield a zero average payoff $\mathbb{E}\left[A_{1}^{T}+p_{1} A_{1}^{N}\right]=0$. Given that $p_{1}^{G}>p_{1}^{B}$, the government makes a net gain in the bad state and a net loss in the good state. Moreover, given that tradable bonds pay a lower expected return than non-tradable bonds in a fragile equilibrium, the portfolio will cost $q_{0}^{T} A_{1}^{T}+q_{0}^{N} A_{1}^{N}>0$ at date 0 .

Condition (26) ensures that the net portfolio gain in the bad state is large enough to cover the difference $\hat{M}-M^{B}$. This shifts up the resources available in the bad equilibrium, moving us from the situation depicted in panel (a) of Figure 4 to the situation depicted in panel (b), and thus eliminating the bad equilibrium. This is our main result on the ex post effects of reserve accumulation: reserves allow the government to hedge against the bad equilibrium state and, by boosting the government's resources in that state, end up eliminating that equilibrium. ${ }^{18}$

The results above provide a rationale for some recent empirical findings. Obstfeld, Shambaugh, and Taylor (2010) show that the size of the banking sector liabilities is an important predictor in explaining the accumulation of foreign currency reserves by emerging markets. In our model, we can compare two economies that have multiple equilibria at $\underline{K}$ and $K^{*}$, have the same foreign net position $a_{1}^{T}-b_{1}^{T}$, and are identical in all other respects except for

\footnotetext{
${ }^{18}$ Conditions (27) and (28) are needed to make sure that the portfolio $\left(A_{1}^{T}, A_{1}^{N}\right)$ is feasible. In particular, condition (27) ensures that the government has sufficient fiscal capacity to cover the portfolio losses in the good state. Condition (28) ensures that it has sufficient fiscal capacity to cover the ex ante cost of reserve accumulation.
} 
the balance sheet of the financial sector at date 1 , that is, for the debt levels $b_{1}^{N}$ and $b_{1}^{T}$. The conditions in Proposition 9 imply the following: ${ }^{19}$

Remark 1 (Reserves and banks' balance sheets). Between the two economies described above, the one with more bank debt requires a higher value of $A_{1}^{T}$ to rule out the bad equilibrium.

Leverage in the banking sector reduces banks' net worth in a crisis, thus requiring a larger government buffer to eliminate the bad equilibrium.

A second remark comes out of our analysis.

Remark 2 (Unused reserves). Reserves can play a useful role in credibly ruling out financial panics and yet never be used in equilibrium.

When the conditions in Proposition 9 are satisfied, the government doesn't intervene in equilibrium and rebates the reserves back to the households. However, the presence of reserves is important to rule out the bad equilibrium. This remark connects our analysis to another empirical observation: emerging markets seem to hold on to their stocks of reserves, even in times of distress. Aizenman and Sun (2012) provide evidence of this type of behavior-which they dub "fear of losing international reserves"-looking at emerging economies' response to the global downturn of 2009.

\subsection{Anticipated interventions}

We now consider the case of a fully expected intervention, that is, we assume that agents correctly anticipate that the government will use reserves optimally at $t=1$ to eliminate the bad equilibrium.

Suppose, in particular, that we start at a fragile equilibrium and the government takes positions that satisfy the conditions in Proposition 9. If all agents correctly anticipate that the government will intervene and eliminate the bad equilibrium, the positions they take at date 0 will adjust. In particular, it is possible to show that there is an equilibrium in which the values of $b_{1}^{T}-A_{1}^{T}$ and $b_{1}^{N}-A_{1}^{N}$ are equal to the values of $b_{1}^{T}$ and $b_{1}^{N}$ in the safe equilibrium constructed in Proposition 5 and the conditions of Proposition 9 are satisfied, so there is a unique (good) continuation equilibrium. This means that the consolidated dollar debt of the banks and the government is lower, and their consolidated peso debt is larger relative to the original fragile equilibrium. In other words, increased dollar holdings by the

\footnotetext{
${ }^{19}$ Notice that the value of $\hat{M}$ depends on the net foreign position of the country, but not on individual balance sheets.
} 
government are not undone by increased dollar borrowing by the banks. We summarize this finding in the next remark.

Remark 3 (Catalytic reserves). When reserves are large enough to eliminate the bad equilibrium, their presence can lead to a higher net consolidated dollar position of banks and the government.

Here the interesting observation is that banks do not have incentives to undo the positive foreign currency position of the government by borrowing more in foreign currency. In other words, the presence of credible intervention at date $t=1$ does not induce more risk taking by banks at $t=0$ as the usual moral hazard logic would suggest, and anticipated government rescues do not lead to more risk taking.

To understand the logic behind this result, it is useful to identify two opposing channels through which government intervention affects banks' behavior ex ante.

First, if we fix the interest rates in tradables and non-tradables at date 0 , there is a direct effect of intervention that leads banks to issue more tradable debt. The argument is as follows. As argued in Section 4, the presence of the bad equilibrium gives banks an incentive to borrow less in tradables, as the marginal value of net worth is higher and tradable debt increases in value in the bad equilibrium. Therefore, when the bad equilibrium is removed, the incentive to borrow in tradables goes up. This is the traditional moral hazard mechanism, where reducing the risk to which banks are exposed (by eliminating the bad equilibrium) would lead to increased risk taking.

Second, there is a general equilibrium effect that works in the opposite direction. When government interventions remove the bad equilibrium, domestic savers are no longer concerned about a large depreciation correlated to a contraction in consumption. Hence, savers will demand more non-tradable denominated assets. This force pushes down the interest rate differential between tradable and non-tradable denominated debt and induces banks to borrow more in non-tradables.

Our argument above shows that the general equilibrium effect dominates in our economy.

\section{Conclusion}

Our model provides a novel perspective on financial dollarization in emerging markets, pointing out the interaction between financial instability and the precautionary motive of domestic savers. We have used our model to study the ex post and ex ante effects of lending of last resort, introducing a notion of fiscally credible interventions. Our analysis provides 
a rationale for the view that official foreign currency reserves support financial stability, as they improve the credibility of domestic authorities to intervene in financial panics.

Our model is very stylized and abstracts from a numer of interesting policy issues.

First, we leave aside the role of monetary policy. Our model can be interpreted as making the implicit assumption that the domestic monetary authority is committed to keep the price of non-tradables stable. It would be interesting to model explicitly monetary policy in an environment with nominal rigidities, to capture important dilemmas faced by monetary policy both ex post and ex ante. Ex post, the monetary authority faces the problem that a monetary expansion causes a nominal devaluation, which increases the burden of dollar debt. Ex ante, the monetary authority faces the problem that agents taking domestic currency positions are afraid of future inflation in financial crises. We leave these issues to future research.

Second, in our paper, the role of foreign currency reserves is to boost the fiscal position of the domestic government in the event of a crisis. There are additional reasons why dollar reserves can help support a financial system in distress. In particular, currency market interventions can be used to dampen movements in the exchange rate, reducing the burden of foreign currency debt. ${ }^{20}$ Capturing this role would require introducing additional frictions in currency markets, which is outside the scope of the present paper.

The central mechanism of our paper is that private savers do not internalize the effect of their portfolio choices on the financial fragility of the economy. The logic of this mechanism can be extended beyond the specific environment considered here, where savers only choose the currency composition of their portfolio. In ongoing work, we explore this mechanism in a more general dynamic macro-financial model in which borrowers and lenders trade state contingent claims, and study its implications for aggregate volatility.

\footnotetext{
${ }^{20}$ Ilzetzki, Reinhart, and Rogoff (2017) interpret reserve accumulation by emerging economies as a tool to reduce exchange rate volatility.
} 


\section{References}

Aghion, Philippe, Philippe Bacchetta, and Abhijit Banerjee. 2001. "Currency crises and monetary policy in an economy with credit constraints." European economic review 45 (7):1121-1150.

- 2004. "A corporate balance-sheet approach to currency crises." Journal of Economic theory $119(1): 6-30$.

Aguiar, Mark and Gita Gopinath. 2007. "Emerging market business cycles: The cycle is the trend." Journal of Political Economy 115 (1):69-102.

Aizenman, Joshua and Yi Sun. 2012. "The financial crisis and sizable international reserves depletion: From "fear of floating" to the "fear of losing international reserves"?" International Review of Economics E Finance 24:250-269.

Arteta, Carlos O. 2005. "Exchange rate regimes and financial dollarization: Does flexibility reduce currency mismatches in bank intermediation?" Topics in Macroeconomics 5 (1).

Bianchi, Javier, Juan Carlos Hatchondo, and Leonardo Martinez. 2012. “International reserves and rollover risk." Tech. rep., National Bureau of Economic Research.

Borri, Nicola and Adrien Verdhelan. 2013. "Sovereign Risk Premia." Manuscript, MIT Sloan.

Brunnermeier, Markus K and Yuliy Sannikov. 2014. "A macroeconomic model with a financial sector." The American Economic Review 104 (2):379-421.

Burnside, Craig, Martin Eichenbaum, and Sergio Rebelo. 2001a. "Hedging and financial fragility in fixed exchange rate regimes.” European Economic Review 45 (7):1151-1193.

- 2001b. "Prospective deficits and the Asian currency crisis." Journal of political Economy 109 (6):1155-1197.

- 2007. "The returns to currency speculation in emerging markets." American Economic Review 97 (2):333-338.

Caballero, Ricardo J, Emmanuel Farhi, and Pierre-Olivier Gourinchas. 2008. "An Equilibrium Model of" Global Imbalances" and Low Interest Rates." The American Economic Review 98 (1):358.

Caballero, Ricardo J and Arvind Krishnamurthy. 2003. "Excessive dollar debt: Financial development and underinsurance." The Journal of Finance 58 (2):867-894. 
Caballero, Ricardo J and Stavros Panageas. 2008. "Hedging sudden stops and precautionary contractions." Journal of Development Economics 85 (1):28-57.

Chang, Roberto and Andres Velasco. 2000. "Financial fragility and the exchange rate regime." Journal of economic theory 92 (1):1-34.

- 2001. "A model of financial crises in emerging markets." Quarterly Journal of Economics :489-517.

Corsetti, Giancarlo, Paolo Pesenti, and Nouriel Roubini. 1999. "Paper tigers?: A model of the Asian crisis." European Economic Review 43 (7):1211-1236.

Dalgic, Husnu. 2017. "Financial Dollarization in Emerging Markets as an Insurance Mechanism." Manuscript, Northwestern University.

De Nicoló, Gianni, Patrick Honohan, and Alain Ize. 2003. Dollarization of the banking system: good or bad? 3-146. International Monetary Fund.

Diamond, Douglas W and Philip H Dybvig. 1983. "Bank runs, deposit insurance, and liquidity." Journal of Political Economy :401-419.

Du, Wenxin and Jesse Schreger. 2016. "Sovereign Risk, Currency Risk, and Corporate Balance Sheets." Manuscript, Columbia Business School.

Durdu, Ceyhun Bora, Enrique G Mendoza, and Marco E Terrones. 2009. "Precautionary demand for foreign assets in Sudden Stop economies: An assessment of the New Mercantilism." Journal of development Economics 89 (2):194-209.

Ennis, Huberto M and Todd Keister. 2009. "Bank runs and institutions: The perils of intervention." The American Economic Review 99 (4):1588-1607.

Fahri, Emmanuel and Matteo Maggiori. 2017. "A Model of the International Monetary System." Forthcoming, Quarterly Journal of Economics.

Farhi, Emmanuel and Jean Tirole. 2012. "Collective moral hazard, maturity mismatch, and systemic bailouts." The American Economic Review 102 (1):60-93.

Gertler, Mark and Nobuhiro Kiyotaki. 2010. "Financial intermediation and credit policy in business cycle analysis." Handbook of Monetary Economics 3 (3):547-599.

- 2015. "Banking, liquidity, and bank runs in an infinite horizon economy." The American Economic Review 105 (7):2011-2043.

Gopinath, Gita and Jeremy C Stein. 2018. "Banking, Trade, and the making of a Dominant Currency." Tech. rep., National Bureau of Economic Research. 
Gourinchas, Pierre-Olivier and Olivier Jeanne. 2013. "Capital flows to developing countries: The allocation puzzle." Review of Economic Studies 80 (4):1484-1515.

He, Zhiguo and Arvind Krishnamurthy. 2012. "Intermediary Asset Pricing." The American Economic Review 20:1-42.

—_. 2015. "A Macroeconomic Framework for Quantifying Systemic Risk." Manuscript, Stanford GSB.

Hernandez, Juan. 2017. "How International Reserves reduce the Probability of Debt Crises." Manuscript, University of Pennsylvania.

Hur, Sewon and Illenin O Kondo. 2016. "A theory of rollover risk, sudden stops, and foreign reserves." Journal of International Economics 103:44-63.

Ilzetzki, Ethan, Carmen M. Reinhart, and Kenneth S. Rogoff. 2017. “Exchange arrangements entering the 21st century: Which anchor will hold?" NBER working paper No 23134.

Ize, Alain and Eduardo Levy-Yeyati. 2003. "Financial dollarization." Journal of International Economics 59 (2):323-347.

Jeanne, Olivier and Romain Rancière. 2011. “The optimal level of international reserves for emerging market countries: a new formula and some applications." The Economic Journal 121 (555):905-930.

King, Mervyn. 2006. "Reform of the International Monetary Fund." Speech at the Indian Council for Research on International Economic Relations.

Krugman, Paul. 1999. "Balance sheets, the transfer problem, and financial crises." In International finance and financial crises: Essays in Honor of Robert P Flood, edited by A. Razin P. Isard and A. Rose. Springer, 31-55.

Levy-Yeyati, Eduardo. 2006. "Financial dollarization: evaluating the consequences." Economic Policy 21 (45):62-118.

Maggiori, Matteo. 2017. "Financial intermediation, international risk sharing, and reserve currencies." Forthcoming, American Economic Review.

Maggiori, Matteo, Brent Nieman, and Jesse Schreger. 2017. “Unpacking Global Capital Flows." Manuscript, Harvard.

Mendoza, Enrique G. 2010. "Sudden stops, financial crises, and leverage." The American Economic Review 100 (5):1941-1966. 
Mendoza, Enrique G, Vincenzo Quadrini, and Jose-Victor Rios-Rull. 2009. "Financial integration, financial development, and global imbalances." Journal of Political economy 117 (3):371-416.

Obstfeld, Maurice, Jay C Shambaugh, and Alan M Taylor. 2010. “Financial stability, the trilemma, and international reserves." American Economic Journal: Macroeconomics $2(2): 57-94$.

Rampini, Adriano A and S Viswanathan. 2010. "Collateral, risk management, and the distribution of debt capacity." The Journal of Finance 65 (6):2293-2322.

Rappoport, Veronica. 2009. "Persistence of dollarization after price stabilization." Journal of Monetary Economics 56 (7):979-989.

Robatto, Roberto. 2017. "Bank Runs, Fire Sales, and Policy Interventions: Panic versus Fundamentals." Working Paper, University of Wisconsin.

Salomao, Juliana and Liniana Varela. 2017. "Exchange Rate Exposure and Firm Dynamics." Manuscript, Carlson School of Management.

Schneider, Martin and Aaron Tornell. 2004. "Balance sheet effects, bailout guarantees and financial crises." The Review of Economic Studies 71 (3):883-913.

Tourre, Fabrice. 2017. "A Macro-Finance Approach to Sovereign Debt Spreads and Returns." Manuscript, University of Chicago.

Wiriadinata, Ursula. 2017. "External Debt, Currency Risk, and International Monetary Policy Transmission." Manuscript, University of Chicago. 


\section{Appendix}

\section{Derivations for equation (6)}

The consumer optimality conditions in a continuation equilibrium can be derived following standard steps and take the form

$$
\begin{gathered}
\omega\left(c_{1}^{T}\right)^{\omega(1-\gamma)-1}\left(c_{1}^{N}\right)^{(1-\omega)(1-\gamma)}=\lambda \\
(1-\omega)\left(c_{1}^{T}\right)^{\omega(1-\gamma)}\left(c_{1}^{N}\right)^{(1-\omega)(1-\gamma)-1}=\lambda p_{1} \\
\beta \omega\left(c_{2}^{T}\right)^{\omega(1-\gamma)-1}\left(c_{2}^{N}\right)^{(1-\omega)(1-\gamma)}=\lambda \beta \\
\beta(1-\omega)\left(c_{2}^{T}\right)^{\omega(1-\gamma)}\left(c_{2}^{N}\right)^{(1-\omega)(1-\gamma)-1}=\lambda \beta p_{2},
\end{gathered}
$$

where $\lambda$ is the Lagrange multiplier on the intertemporal budget constraint. Combining (A.1), (A.3), and the market clearing condition $c_{t}^{N}=e^{N}$, we get $c_{1}^{T}=c_{2}^{T}$. Combining (A.2) and (A.4) we then get $p_{1}=p_{2}=p$. Combining (A.1) and (A.2), we also get $c_{t}^{T} /\left(p_{1} c_{1}^{N}\right)=$ $\omega /(1-\omega)$, and similarly we get the same relation at $t=2$. Substituting these conditions in the intertemporal budget constraint, we obtain

$$
c_{1}^{T}=c_{2}^{T}=\frac{\omega}{1+\beta} W, \quad c_{1}^{N}=c_{2}^{N}=\frac{1}{p} \frac{1-\omega}{1+\beta} W,
$$

where

$$
W=a_{1}^{T}+p a_{1}^{N}+w_{1}+\beta w_{2}+p\left(e_{c, 1}^{N}+\beta e_{c, 2}^{N}\right)
$$

is the total wealth of the consumers at date 1 . Setting $c_{1}^{N}=e^{N}$ gives equation (6) in the text.

\section{Proof of Proposition 1}

If $\left\{a_{1}^{T}, a_{1}^{N}, b_{1}^{T}, b_{1}^{N}, K_{1}\right\}$ satisfy (8), we have that $\mathcal{P}($.$) is increasing in K$ and concave. Let $p^{*}=\mathcal{P}\left(K^{*}\right)$ and $\underline{p}=\mathcal{P}(\underline{K})$. We can have three types of equilibria: either we have

$$
\underline{K} \geq \frac{1}{1-\beta \theta}\left[\alpha K_{1}^{\alpha}-b_{1}^{T}+\underline{p}\left(e_{b, 1}^{N}-b_{1}^{N}\right)\right]
$$

and we have an equilibrium with $\underline{K}=\mathcal{K}(\underline{p})$ and $\underline{p}=\mathcal{P}(\underline{K})$; or we have

$$
K^{*} \leq \frac{1}{1-\beta \theta}\left[\alpha K_{1}^{\alpha}-b_{1}^{T}+p^{*}\left(e_{b, 1}^{N}-b_{1}^{N}\right)\right]
$$


and we have an equilibrium with $K^{*}=\mathcal{K}\left(p^{*}\right)$ and $p^{*}=\mathcal{P}(K)$; or we have

$$
K=\frac{1}{1-\beta \theta}\left[\alpha K_{1}^{\alpha}-b_{1}^{T}+\mathcal{P}(K)\left(e_{b, 1}^{N}-b_{1}^{N}\right)\right]
$$

for some $\left(\underline{K}, K^{*}\right)$, and we have an interior equilibrium. If the first two types of equilibria do not exist, then the third type of equilibrium must exist by a continuity argument. This establishes existence.

Let us now show that if there are multiple equilibria, one of them must be of the first type. By contradiction, we show that if a first type equilibrium does not exist, then the equilibrium is unique. The function $h(K)=\frac{1}{1-\beta \theta}\left[\alpha K_{1}^{\alpha}-b_{1}^{T}+\mathcal{P}(K)\left(e_{b, 1}^{N}-b_{1}^{N}\right)\right]$ is concave, from the concavity of $\mathcal{P}$ and $b_{1}^{N} \leq e_{b, 1}^{N}$. If an equilibrium of the first type does not exist, then $h(\underline{K})>\underline{K}$ and two cases are possible: either the function $h$ crosses the $45^{\circ}$ line from above at some $K \in\left(\underline{K}, K^{*}\right)$, in which case that is the unique equilibrium, or the function remains above the $45^{\circ}$ line on the whole interval, in which case $h\left(K^{*}\right) \geq K^{*}$ and there is a unique equilibrium at $K^{*}$.

\section{Proof of Proposition 2}

Points (i)-(iii) and the consumers' part of point (iv) follow immediately from the fact that $p_{1}$ and $K_{2}$ are lower in the crisis equilibrium. For the entrepreneurs, we have that their consumption in period 2 is

$$
\frac{r_{2}-\theta}{1-\beta \theta} n_{1}
$$

If $K_{2} \in\left(\underline{K}, K^{*}\right)$, this expression becomes

$$
\frac{r_{2}-\theta}{1-\beta \theta} n_{1}=\left(r_{2}-\theta\right) K_{2}=\alpha K_{2}^{\alpha}-\theta K_{2}
$$

where the first equality uses the banks' budget constraint and the fact that the banks are constrained when $K_{2}$ is in that interval, and the second equality uses the definition of the rental rate of capital.

If there is an equilibrium at $\underline{K}$, then

$$
\frac{r_{2}-\theta}{1-\beta \theta} n_{1} \leq\left(\alpha \underline{K}^{\alpha-1}-\theta\right) \underline{K}=\alpha \underline{K}^{\alpha}-\theta \underline{K}
$$


whereas if there is an equilibrium at $K^{*}$,

$$
\frac{r_{2}-\theta}{1-\beta \theta} n_{1} \geq\left(\alpha\left(K^{*}\right)^{\alpha-1}-\theta\right) K^{*}=\alpha\left(K^{*}\right)^{\alpha}-\theta K^{*}
$$

These derivations and the concavity of $\alpha K^{\alpha}-\theta K$ imply that a sufficient condition for the banker to be better off at any equilibrium with $K_{2}>\underline{K}$, than at the crisis equilibrium with $\underline{K}$, is

$$
\alpha\left(K^{*}\right)^{\alpha}-\theta K^{*}>\alpha \underline{K}^{\alpha}-\theta \underline{K} .
$$

Given the definitions of $K^{*}$ and $\underline{K}$, this inequality is equivalent to condition (11) in the statement of the proposition.

\section{Proof of Proposition 3}

The proof is by construction. Fix the wages and rental rates that prevail in the good and the bad equilibria under $\left\{a_{1}^{T}, a_{1}^{N}, b_{1}^{T}, b_{1}^{N}, K_{1}\right\}$. If condition (15) is satisfied, there exists a $\gamma>0$ such that

$$
\left(\frac{w_{1}+w_{2}^{B}+a_{1}^{T}}{w_{1}+w_{2}^{G}+a_{1}^{T}}\right)^{\omega(1-\gamma)-1}=\frac{r_{2}^{B}-\theta}{r_{2}^{G}-\theta} .
$$

The above condition guarantees that the asset positions are consistent with consumers' and banks' optimality. We now show that we can select initial positions $\left\{a_{0}^{T}, a_{0}^{N}, b_{0}^{T}, b_{0}^{N}, K_{0}\right\}$ such that all the remaining equilibrium conditions of the model at date $t=0$ are satisfied. As we have some degree of freedom, we set $a_{0}^{N}=b_{0}^{N}=0$.

Pick any probabilities $\pi^{G}, \pi^{B}$ and set $c_{0}^{T}$ to satisfy the consumers' Euler equation

$$
\left(c_{0}^{T}\right)^{\omega(1-\gamma)-1}=\sum_{s=G, B} \pi^{s}\left(c_{1}^{T, s}\right)^{\omega(1-\gamma)-1} .
$$

We can then choose $a_{0}^{T}$ to satisfy the consumers' budget constraint at $t=0$ :

$$
c_{0}^{T}+p_{0} e^{N}+\beta a_{1}^{T}=p_{0} e_{c, 0}^{N}+w_{0}+a_{0}^{T}
$$

where

$$
p_{0}=\frac{1-\omega}{\omega} \frac{c_{0}^{T}}{e^{N}}
$$

guarantees that the market for non-tradable goods clears. So, households are optimizing, and their budget constraint is satisfied.

Assuming that the collateral constraint of the banks is slack, we have that optimal capital 
choice at date $t=0$ solves

$$
\lambda_{b, 0}=\mathbb{E}\left[\lambda_{b, 1}\right] r_{1} .
$$

Combining the above equation with the banks' optimality condition for tradable denominated bonds, we obtain $K_{1}=K^{*}$. Thus, the budget constraint of the banks is satisfied if

$$
K^{*}=\alpha K_{0}^{\alpha}+p_{0} e_{b, 0}^{N}-b_{0}^{T}+\beta b_{1}^{T} .
$$

For any $K_{0}$, there always exists a $b_{0}^{T}$ that guarantees that the above constraint holds. Moreover, the collateral constraint $b_{1}^{T} \leq \theta K_{1}$ is satisfied by construction, verifying the assumption that the banks' collateral constraint is slack. Thus, the bankers are also optimizing, and their constraint is satisfied.

\section{Proof of Proposition 4}

Having stable multiple equilibria ex ante requires that we have a pair of capital stocks $\left(\underline{K}, K_{2}\right)$ such that

$$
\left(\frac{w_{1}+w_{2}^{B}+a_{1}^{T}}{w_{1}+w_{2}^{G}+a_{1}^{T}}\right)^{\omega(1-\gamma)-1}=\frac{r_{2}^{B}-\theta}{r_{2}^{G}-\theta},
$$

where wages and rental rates are derived from the two capital stocks. This is impossible if

$$
\left(\frac{w_{1}+w_{2}^{B}+a_{1}^{T}}{w_{1}+w_{2}^{G}+a_{1}^{T}}\right)^{\omega(1-\gamma)-1}<\frac{r_{2}^{B}-\theta}{r_{2}^{G}-\theta}
$$

for all pairs $\left(K_{2}, \underline{K}\right)$ with $K_{2} \in\left[\underline{K}, K^{*}\right]$. To find sufficient conditions for this inequality, let us study the function

$$
f(k)=\ln \left(\alpha k^{\alpha-1}-\theta\right)+(\omega(\gamma-1)+1) \ln \left(w_{1}+\beta(1-\alpha) k^{\alpha}+a_{1}^{T}\right) .
$$

If $f^{\prime}(k)<0$ for all $k \in\left[\underline{K}, K^{*}\right]$, then the above inequality holds. The derivative of $f$ is

$$
f^{\prime}(k)=\frac{\alpha(\alpha-1) k^{\alpha-2}}{\alpha k^{\alpha-1}-\theta}+(1+\omega(\gamma-1)) \frac{\beta(1-\alpha) \alpha k^{\alpha-1}}{w_{1}+\beta(1-\alpha) k+a_{1}^{T}}
$$

and has the same sign as

$$
\left(\beta \alpha k^{\alpha-1}-\beta \theta\right)(1+\omega(\gamma-1)) k-w_{1}-\beta(1-\alpha) k-a_{1}^{T} .
$$


Since $w_{1} \geq 0$ and $\beta \alpha k^{\alpha-1} \leq \phi$ and we are assuming $a_{1}^{T} \geq 0$, the last expression is bounded above by

$$
(\phi-\beta \theta)(1+\omega(\gamma-1)) k-\beta(1-\alpha) k
$$

which is negative by assumption.

\section{Proof of Proposition 5}

Some algebra shows that consumption of tradables in a fragile equilibrium satisfies

$$
\begin{aligned}
& c_{0}^{T}=\psi_{0}\left(w_{0}+a_{0}^{T}-\beta a_{1}^{T}\right), \\
& c_{1}^{T, s}=\psi_{1}\left(w_{1}+\beta w_{2}^{s}+a_{1}^{T}\right),
\end{aligned}
$$

for $s=\{B, G\}$, where

$$
\begin{gathered}
\psi_{0}=\frac{\omega e^{N}}{\omega e^{N}+(1-\omega) e_{b, 0}^{N}}, \\
\psi_{1}=\frac{\omega e^{N}}{(1+\beta) \omega e^{N}+(1-\omega)\left(e_{b, 1}^{N}+\beta e_{b, 2}^{N}\right)} .
\end{gathered}
$$

The Euler equation for consumers

$$
\left(c_{0}^{T}\right)^{\omega(1-\gamma)-1}=\sum_{s} \pi^{s}\left(c_{1}^{T, s}\right)^{\omega(1-\gamma)-1}
$$

implies

$$
c_{0}^{T}<\mathbb{E}_{0}\left[c_{1}^{T, s}\right]<c^{T, G},
$$

which implies

$$
\left(\frac{1}{\psi_{0}}+\beta \frac{1}{\psi_{1}}\right) c_{0}^{T}<\frac{c_{0}^{T}}{\psi_{0}}+\beta \frac{c_{1}^{T, G}}{\psi_{1}}=\frac{w_{0}+w_{1}+\beta w_{2}^{G}+a_{0}^{T}}{1+\beta+\beta^{2}}
$$

In a safe equilibrium, consumption of tradables must be constant $c_{0}^{T}=c_{1}^{T}=c_{2}^{T}=\hat{c}^{T}$. Therefore, to construct a safe equilibrium, we look for a vector $\hat{c}^{T}, \hat{p}, \hat{n}_{1}, \hat{K}_{2}$ that satisfies the following four equations:

$$
\left(\frac{1}{\psi_{0}}+\beta \frac{1}{\psi_{1}}\right) \hat{c}^{T}=w_{0}+\beta w_{1}+\beta^{2}(1-\alpha) \hat{K}_{2}^{\alpha}+a_{0}^{T}
$$




$$
\begin{gathered}
\hat{p}=\frac{1-\omega}{\omega} \frac{\hat{c}^{T}}{e^{N}}, \\
\hat{n}_{1}=\frac{1}{\beta}\left[\hat{p}\left(e_{b, 0}^{N}+\beta e_{b, 1}^{N}\right)+\alpha K_{0}^{\alpha}-b_{0}^{T}\right], \\
\hat{K}_{2}=\min \left\{\frac{1}{1-\beta \theta} \hat{n}_{1}, K^{*}\right\} .
\end{gathered}
$$

The equation for banks' net worth follows from the fact that we constructed fragile equilibria with $K_{1}=K^{*}$, so the rate of return on banks' net worth is $1 / \beta$ between periods 0 and 1.

It is possible to use equation (A.5) together with monotonicity and concavity properties of the functions involved to show that the four equations above have a unique solution with

$$
\hat{K}_{2} \geq K_{2}^{G}, \hat{n}_{1} \geq n_{1}^{G}, \hat{c}^{T}>c_{0}^{T}
$$

We can then construct a safe equilibrium based on the allocation just derived and set the positions in non-tradables to $\hat{a}_{1}^{N}=\hat{b}_{1}^{N}=e_{b}^{N}$.

\section{Proof of Proposition 6}

Before proving the proposition, we state and prove three preliminary lemmas.

To ensure that condition (21) is satisfied, the government must choose an allocation that is in one of two regions: the region $k_{2} \leq K_{2}=\underline{K}$ and the region $k_{2}=K_{2} \geq \underline{K}$. The next two lemmas characterize the optimal solution when the opimal $k_{2}$ is in one of these two regions.

Lemma 1. If the government optimum satisfies $k_{2} \leq K_{2}=\underline{K}$ and $k_{2}^{B} \in\left[\frac{n_{1}}{1-\beta \theta}, \frac{M}{1-\beta \theta}\right]$, then the optimum is at the bad equilibrium allocation.

Proof. When $k_{2} \leq K_{2}=\underline{K}$, the first-order conditions for the optimal choice of $\left(c^{T}, c_{b}^{T}, k_{2}\right)$ are

$$
\begin{aligned}
U_{c^{T}}\left(c^{T}, e^{N}\right) & =\lambda \\
\beta \Phi & =\beta \lambda-\mu \\
\lambda(\phi-1) & =\mu\left(\alpha \underline{K}^{\alpha-1}-\theta\right)+\delta_{u}-\delta_{l},
\end{aligned}
$$

where $\lambda$ and $\mu$ are the Lagrange multipliers of constraints (19) and (20), and $\delta_{u}$ and $\delta_{l}$ are the Lagrange multipliers on the upper and lower bounds in (22).

If $k_{2}^{B} \in\left[\frac{n_{1}}{1-\beta \theta}, \frac{M}{1-\beta \theta}\right]$, the bad equilibrium allocation is feasible and we can check that the 
first-order conditions (A.6)-(A.8) are satisfied at the bad equilibrium allocation, with $\delta_{u}=$ $\delta_{l}=0$. Solving for $\lambda$ and $\mu$ from (A.6) and (A.7), substituting in (A.8), using $\phi=\beta \alpha \underline{K}^{\alpha-1}$, and rearranging gives

$$
\Phi \beta \frac{r_{2}^{B}-\theta}{1-\beta \theta}-U_{c^{T}}\left(c^{T, B}, e^{N}\right)=0,
$$

where the equality follows from our choice of $\Phi$ and the equilibrium conditions of a fragile equilibrium.

Define the value of the social welfare function at the bad equilibrium:

$$
W^{B} \equiv(1+\beta) U\left(c^{T, B}, e^{N}\right)+\Phi \beta c_{b}^{T, B}
$$

We can then state the next lemma.

Lemma 2. If the government optimum satisfies $k_{2}=K_{2} \geq \underline{K}$, it also satisfies

$$
\begin{aligned}
k_{2} & =K_{2}=\min \left\{\frac{M}{1-\beta \theta}, K^{*}\right\}, \\
c^{T} & =\min \left\{\frac{1}{1+\beta}\left(a_{1}^{T}-b_{1}^{T}+K_{1}^{\alpha}+\beta(1-\alpha) K_{2}^{\alpha}-(1-\beta \theta) K_{2}\right), c^{T, G}\right\}, \\
c_{b}^{T} & =\frac{1}{\beta}\left(a_{1}^{T}-b_{1}^{T}+K_{1}^{\alpha}+\beta K_{2}^{\alpha}-K_{2}-(1+\beta) c^{T}\right) .
\end{aligned}
$$

Proof. The first-order conditions for $\left(c^{T}, c_{b}^{T}, k_{2}\right)$ in this case are

$$
\begin{aligned}
U_{c^{T}}\left(c^{T}, e^{N}\right) & =\lambda \\
\beta \Phi & =\beta \lambda-\mu \\
\lambda\left(\alpha \beta K_{2}^{\alpha-1}-1\right) & =\mu\left(\alpha^{2} K_{2}^{\alpha-1}-\theta\right)+\delta_{u}-\delta_{l},
\end{aligned}
$$

where the Lagrange multipliers are labeled as in the previous lemma. To show that the allocation in (A.11)-(A.13) satisfies these first-order conditions, we consider three cases.

First, consider the case in which $M /(1-\beta \theta)<K^{*}$ and

$$
c^{T, G} \leq \frac{1}{1+\beta}\left(a_{1}^{T}-b_{1}^{T}+K_{1}^{\alpha}+\beta(1-\alpha) K_{2}^{\alpha}-(1-\beta \theta) K_{2}\right) .
$$

In this case, equation (A.12) yields $c^{T}=c^{T, G}$, and, using inequality (A.17) and condition (A.13), it is easy to show that the participation constraint (20) is slack. Consistent with a slack participation constraint, equations (A.14) and (A.15) yield $\mu=0$, as $U_{c^{T}}=\Phi$ at the good equilibrium allocation. Since $k_{2}$ is at its upper bound, we set $\delta_{l}=0$ and we need 
to check that $\delta_{u} \geq 0$. The value of $\delta_{u}$ can be derived from equation (A.16) and is positive because $\mu=0$ and $\alpha \beta K_{2}^{\alpha-1}>1$ from $K_{2}<K^{*}$.

Second, consider the case in which $M /(1-\beta \theta)<K^{*}$ and

$$
c^{T, G}>\frac{1}{1+\beta}\left(a_{1}^{T}-b_{1}^{T}+K_{1}^{\alpha}+\beta(1-\alpha) K_{2}^{\alpha}-(1-\beta \theta) K_{2}\right) .
$$

In this case, equation (A.12) yields $c^{T}<c^{T, G}$, and, using inequality (A.18) and condition (A.13), it is possible to check that the participation constraint (20) is binding. Consistent with a binding constraint, equations (A.14) and (A.15) yield $\mu>0$ (using $c^{T}<c^{T, G}$, $U_{c^{T}}\left(c^{T, G}, e^{N}\right)=\Phi$, and strict concavity of $U$ ). Again, $k_{2}$ is at its upper bound, so we need to check that $\delta_{u} \geq 0$. In this case, we can write

$$
\beta \delta_{u}=\beta \lambda\left(\alpha \beta K_{2}^{\alpha-1}-1\right)-\mu\left(\alpha^{2} \beta K_{2}^{\alpha-1}-\beta \theta\right)
$$

and the argument that $\delta_{u} \geq 0$ follows from two inequalities: $\beta \lambda>\mu$-which follows immediately from (A.15) —and

$$
\alpha \beta K_{2}^{\alpha-1}-1>\alpha^{2} \beta K_{2}^{\alpha-1}-\beta \theta
$$

To prove the last inequality, notice that it is equivalent to requiring that the expression

$$
\frac{1}{1+\beta}\left(a_{1}^{T}-b_{1}^{T}+K_{1}^{\alpha}+\beta(1-\alpha) K_{2}^{\alpha}-(1-\beta \theta) K_{2}\right)
$$

has a positive derivative with respect to $K_{2}$. This expression is the first expression inside the min operator in (A.12) and is a concave function of $K_{2}$. Moreover, it is possible to prove that $c^{T, G}$ is strictly lower than this expression at $K_{2}=K^{*}$. This implies that the derivative of this function must be positive for any $K_{2}<K^{*}$ that satisfies (A.18).

Third, consider the case $M /(1-\beta \theta) \geq K^{*}$. In this case, the good equilibrium allocation can be implemented and the first-order conditions are all satisfied with $\mu=\delta_{u}=\delta_{l}=0$.

In order to define the cutoff $\hat{M}$, we first need to define the function $\mathcal{J}(M)$ that gives social welfare at the allocation defined by (A.11)-(A.13) for any given $M$. The next lemma characterizes this function. Define the following values for $M$ :

$$
\underline{M} \equiv(1-\beta \theta) \underline{K}, \quad M^{*}=(1-\beta \theta) K^{*} .
$$

Lemma 3. The function $\mathcal{J}(M)$, is continuous and strictly increasing in $M$ for $M<M^{*}$, and it 
achieves its maximum

$$
J(M)=W^{G} \equiv(1+\beta) U\left(c^{T, G}, e^{N}\right)+\Phi \beta c_{b}^{T, G},
$$

for all $M \geq M^{*}$. It also satisfies

$$
\mathcal{J}(\underline{M})<\mathcal{W}^{B}
$$

Proof. It is straightforward to show that $\mathcal{J}(M)$ is continuous and increasing in $M$, as a higher $M$ relaxes the upper bound constraint on $k_{2}$. Moreover, $\mathcal{J}(M)$ achieves its maximum at the good equilibrium allocation because the government implements this allocation if $M \geq M^{*}$, as shown in Lemma 2 .

To show the inequality $\mathcal{J}(\underline{M}) \leq W^{B}$, notice that the allocation chosen at $\underline{M}$ has $k_{2}=$ $K_{2}=\underline{K}$. So the same allocation is also feasible in the region of allocations considered in Lemma 1. And that lemma shows that the optimum in that set is (if feasible) at the bad equilibrium allocation. It is also easy to show that the latter is a unique local optimum, proving the strict inequality.

We can now define the cutoff $\hat{M}$ and complete our proof. We just proved that $\mathcal{J}(\underline{M})<$ $W^{B}$ and $\mathcal{J}\left(M^{*}\right)=W^{G}$. Since the good equilibrium Pareto dominates, we have $W^{G}>W^{B}$. By continuity of $\mathcal{J}$ there must exist an $M \in\left(\underline{M}, M^{*}\right)$ such that $\mathcal{J}(M)=W^{B}$. Such value is unique since $\mathcal{J}$ is strictly increasing in that interval. Let $\hat{M}$ be that unique value.

If $M<\hat{M}$ and $k_{2}^{B} \in\left[\frac{n_{1}}{1-\beta \theta}, \frac{M}{1-\beta \theta}\right]$, we know from Lemma 1 that the bad equilibrium allocation is the best allocation in the region $k_{2} \leq K_{2}=\underline{K}$. We also know that there can be no solution in the region $k_{2}=K_{2} \geq \underline{K}$ that dominates $W^{B}$ because, by Lemma 2 , such a solution would yield $\mathcal{J}(M)$ and the definition of $\hat{M}$ implies $\mathcal{J}(M)<W^{B}$. This proves part 1 of the proposition.

If $M>\hat{M}$, we know from Lemma 2 that there is a solution in the region $k_{2}=K_{2} \geq \underline{K}$ that is feasible and dominates the best solution in the region $k_{2} \leq K_{2}=\underline{K}$, which yields at most $W^{B}$. This proves part 2 of the proposition.

If $M=\hat{M}$, the government is indifferent between the bad equilibrium and setting $k_{2}=$ $K_{2}=M /(1-\beta \theta)$. In this case, we assume that the government chooses the second solution.

\section{Proof of Proposition 7}

The steps to prove this result are provided in the discussion of Figure 4 in the main text. 


\section{Proof of Proposition 8}

If the actions in the first and second subperiods are simultaneous, the problem of the government becomes

$$
\max _{c^{T}, c_{b}^{T}, k_{2}, K_{2}}(1+\beta) U\left(c^{T}, e^{N}\right)+\Phi c_{b}^{T}
$$

subject to

$$
\begin{aligned}
(1+\beta) c^{T}+\beta c_{b}^{T} & \leq a_{1}^{T}-b_{1}^{T}+K_{1}^{\alpha}+\beta K_{2}^{\alpha}-k_{2}-\phi\left(K_{2}-k_{2}\right) \\
c_{b}^{T} & \geq \alpha K_{2}^{\alpha-1} k_{2}-\theta k_{2} \\
\alpha \beta K_{2}^{\alpha-1} & \geq \phi \text { and } K_{2}-k_{2} \geq 0 \\
\min \left\{\frac{n_{1}\left(c^{T}\right)}{1-\beta \theta}, K^{*}\right\} & \leq k_{2} \leq \min \left\{\frac{M\left(c^{T}, K_{2}\right)}{1-\beta \theta}, K^{*}\right\},
\end{aligned}
$$

where $n_{1}\left(c^{T}\right)$ depends on $c^{T}$ because the latter affects the equilibrium exchange rate, and $M\left(c^{T}, K_{2}\right)$ depends on $c^{T}$ and $K_{2}$ because the former affects net worth through the exchange rate and the latter affects second-period wages and, thus, the tax revenues the government can collect. Note also that $n_{1}\left(c^{T, G}\right) /(1-\beta \theta) \geq K^{*}$ because of the assumption that in the good continuation equilibrium with no interventions, banks are not financially constrained. Note also that $M\left(c^{T, G}, K^{*}\right) /(1-\beta \theta) \geq K^{*}$ even if $\xi=0$. It follows that the allocation of the good continuation equilibrium with no intervention is feasible. It is straightforward to show that it is optimal for the government to implement such an allocation (see the proof of Proposition 6 for the argument).

\section{Proof of Proposition 9}

The steps to prove this result are provided in the main text. 


\title{
Online Appendix to "Financial Crises, Dollarization, AND LENDING OF LAST RESORT IN OPEN ECONOMIES"
}

\author{
By LUIGI Bocola AND GUIDo LORENZONI
}

\section{The decision problem of the government}

The government enters subperiod (ii) and chooses a policy $\left\{\tau_{1}, \tau_{2}, T_{1}, T_{2}, A_{2}^{T}, T_{b}, R\right\}$ that maximizes the social welfare function subject to its budget constraints, feasibility,

$$
\tau_{t} \leq \xi \quad T_{t} \geq 0 \quad-A_{2}^{T} \leq-\underline{A} \quad T_{b} \geq 0 \quad R \leq \beta^{-1} T_{b}
$$

and the optimal behavior of consumers, bankers, and firms.

In this section we show that this problem can be rewritten as choosing an allocation $\left(c^{T}, c_{b}^{T}, k_{2}, K_{2}\right)$ that maximizes social welfare, subject to a set of constraints.

We can start by deriving an intertemporal resource constraint for the economy by consolidating the budget constraints of the government, consumers, and bankers. The budget constraints of the consumers under a government's policy are

$$
\begin{gathered}
c_{1}^{T}+p_{1} c_{1}^{N}+\beta a_{2}^{T} \leq\left(1-\tau_{1}\right) w_{1}+p_{1} e_{c, 1}^{N}+a_{1}^{T}+p_{1}^{N} a_{1}+T_{1} \\
c_{2}^{T}+p_{2} c_{2}^{N} \leq\left(1-\tau_{2}\right) w_{2}+p_{2} e_{c, 2}^{N}+a_{2}^{T}+T_{2} .
\end{gathered}
$$

The budget constraints for the government are

$$
\begin{gathered}
T_{1}+T_{b} \leq \tau_{1} w_{1}-\beta A_{2}^{T} \\
T_{2}-A_{2}^{T} \leq \tau_{2} w_{2}+R .
\end{gathered}
$$

Consolidating the budget constraints of the government with those of the consumers, we have

$$
c_{1}^{T}+\beta c_{2}^{T}+p_{1} c_{1}^{N}+\beta p_{2} c_{2}^{N} \leq w_{1}+\beta w_{2}+p_{1} e_{c, 1}^{N}+\beta p_{2} e_{c, 2}^{N}+a_{1}^{T}+p_{1} a_{1}^{N}+\left(\beta R-T_{b}\right) .
$$

For the banks, we have the budget constraints

$$
\begin{aligned}
& k_{2} \leq n_{1}+\beta b_{2}^{T}+T_{b} \\
& c_{b}^{T} \leq r_{2} k_{2}-b_{2}^{T}-R .
\end{aligned}
$$


Substituting the two expressions above in (OA.1) and using the market clearing conditions for non-tradable goods, for factors of production, and for the $N$-denominated bonds, we obtain the intertemporal resource constraint

$$
c_{1}^{T}+\beta c_{2}^{T}+\beta c_{b}^{T} \leq\left(a_{1}^{T}-b_{1}^{T}\right)+K_{1}^{\alpha}+\beta K_{2}^{\alpha}-k_{2}-\phi\left(K_{2}-k_{2}\right)
$$

Given any government policy, consumers set $c_{1}^{T}=c_{2}^{T}=c^{T}$. Thus, the intertemporal resource constraint becomes

$$
(1+\beta) c^{T}+\beta c_{b}^{T} \leq\left(a_{1}^{T}-b_{1}^{T}\right)+K_{1}^{\alpha}+\beta K_{2}^{\alpha}-k_{2}-\phi\left(K_{2}-k_{2}\right) .
$$

We can also derive a lower bound on the consumption of bankers that must be satisfied under any policy of the government. Using the collateral constraint

$$
b_{2}^{T}+R \leq \theta k_{2}
$$

and the expression for net worth in period 2, we obtain the following restriction on $c_{b}^{T}$ :

$$
c_{b}^{T}=r_{2} k_{2}-b_{2}^{T}-R \geq\left(\alpha K_{2}^{\alpha-1}\right) k_{2}-\theta k_{2}
$$

From these derivations, we have that $\left(c^{T}, c_{b}^{T}\right)$ must satisfy the constraints (OA.2) and (OA.3) under any government policy. We now show that the government can partly control $\left(k_{2}, K_{2}\right)$ by using $\left(T_{b}, R\right)$.

Using the optimality conditions of firms operating with an inferior technology, we have that for any feasible $\left(T_{b}, R\right),\left(k_{2}, K_{2}\right)$ must satisfy

$$
K_{2}-k_{2} \geq 0 \quad \alpha \beta K_{2}^{\alpha-1} \leq \phi,
$$

where at least one of the above inequalities is strict. Note also that for any $\left(T_{b}, R\right)$, we cannot have that $k_{2}=K_{2}>K^{*}$ because the banks would not borrow when $\beta r_{2}>1$. Moreover, because $T_{b} \geq 0$, we must have that

$$
k_{2} \geq \min \left\{\frac{n_{1}}{1-\beta \theta}, K^{*}\right\}
$$

which is the optimal level of investment set by banks when $T_{b}=0$.

It follows that the government can influence $\left(k_{2}, K_{2}\right)$ only when $n_{1} /(1-\beta \theta)<K^{*}$, and as long as $K_{2} \leq K^{*}$. Under these conditions, the collateral constraint of banks necessarily 
binds, which implies that banks use any government transfer to accumulate capital. The maximum transfer that the government can give to the banks is obtained by setting $T_{b}=$ $\xi(1-\alpha) K_{1}^{\alpha}-\beta \underline{A}$ and $R=0$. Thus, the highest level of bank investment that the government can induce satisfies

$$
k_{2} \leq \min \left\{\frac{M}{1-\beta \theta}, K^{*}\right\},
$$

where $M=n_{1}+\xi(1-\alpha) K_{1}^{\alpha}-\beta \underline{A}$.

From here, it follows that choosing a feasible $\left(T_{b}, R\right)$ is equivalent to choosing $\left(K_{2}, k_{2}\right)$ subject to the constraints (OA.4)-(OA.6).

As a result, we can write the decision problem of the government as follows:

$$
W\left(n_{1}, M\right)=\max _{c^{T}, c_{b}^{T}, k_{2}, K_{2}}(1+\beta) U\left(c^{T}, e^{N}\right)+\Phi c_{b}^{T}
$$

subject to

$$
\begin{aligned}
(1+\beta) c^{T}+\beta c_{b}^{T} & \leq a_{1}^{T}-b_{1}^{T}+K_{1}^{\alpha}+\beta K_{2}^{\alpha}-k_{2}-\phi\left(K_{2}-k_{2}\right) \\
c_{b}^{T} & \geq \alpha K_{2}^{\alpha-1} k_{2}-\theta k_{2} \\
\alpha \beta K_{2}^{\alpha-1} & \geq \phi \text { and } K_{2}-k_{2} \geq 0 \\
\min \left\{\frac{n_{1}}{1-\beta \theta}, K^{*}\right\} & \leq k_{2} \leq \min \left\{\frac{M}{1-\beta \theta}, K^{*}\right\},
\end{aligned}
$$

with at least one condition in (OA.9) holding as an equality.

\section{Microfoundations for limited fiscal capacity}

Suppose that firms in the tradable sector can operate in an informal sector that cannot be taxed. Capital and labor can freely move to the informal sector, but labor in the informal sector is less efficient, by a factor $1-\xi$. That is, the production function in the informal sector is

$$
\tilde{y}=\tilde{K}^{\alpha}((1-\xi) \tilde{L})^{1-\alpha}
$$

The wage in the informal sector is

$$
\tilde{w}=(1-\alpha)(1-\tilde{\xi})\left(\frac{\tilde{K}}{(1-\tilde{\xi}) \tilde{L}}\right)^{\alpha}
$$


Optimality for capital in the informal sector requires

$$
\alpha\left(\frac{\tilde{K}}{(1-\tilde{\xi}) \tilde{L}}\right)^{\alpha-1}=r=\alpha\left(\frac{K}{L}\right)^{\alpha-1}
$$

which implies

$$
\frac{\tilde{K}}{(1-\xi) \tilde{L}}=\frac{K}{L}
$$

Workers weakly prefer the formal sector if

$$
(1-\tau)(1-\alpha)\left(\frac{K}{L}\right)^{\alpha} \geq(1-\alpha)(1-\xi)\left(\frac{\tilde{K}}{(1-\xi) \tilde{L}}\right)^{\alpha}=(1-\xi)(1-\alpha)\left(\frac{K}{L}\right)^{\alpha}
$$

that is, if

$$
\tau \leq \xi
$$

If $\tau>\xi$, all labor and capital will shift to the informal sector and tax revenues are zero. If $\tau=\xi$, agents are indifferent and we assume that they choose to work in the formal sector. If $\tau<\xi$, there is no activity in the informal sector and taxes are non-distortionary. Thus, this economy is equivalent to our baseline model where labor taxes are non-distortionary but are bounded above by $\xi$. 